\title{
Landslide influence zone - a hidden hazard
}

\author{
ALEXANDER M. PUZRIN*
}

\begin{abstract}
Inspired by two practical cases in Switzerland, the paper investigates a problem of elevated earth pressures downslope of existing landslides. This problem is relevant for both permanent landslides and one-time events, and of particular practical interest is the area of the stable slope just below the landslide high-pressure compression zone. Intuitively, there should be a transition zone, within which high landslide pressures subside to the far field (at rest) earth pressures in the stable slope. How large is this transition zone and how fast do the earth pressures decrease away from the slide? The paper proposes a basic mechanism of the downhill pressure transfer within the stable part of the slope below a landslide. The mechanism combines the failure at the bottom of the unstable part of the slope with progressive growth of the slip surface into the stable part, accounting for the groundwater flow and potential presence of embedded structures. It allows the determination of the dimensions of the 'landslide influence zone' below the landslide and the lateral earth pressures within it, providing some insights for design considerations and future hazard mapping.
\end{abstract}

KEYWORDS: earth pressure; landslides; soil/structure interaction

\section{INTRODUCTION}

Construction in landslide-prone areas often brings geotechnical engineers to the limits of their knowledge. Earth pressures acting on the structures within the sliding body may significantly differ from those in the stable slopes (e.g. Haefeli, 1944; Brandl \& Dalmatiner, 1988; Chu, 1991; Puzrin \& Sterba, 2006; Puzrin \& Schmid, 2012; Muraro et al., 2015). Past research has attempted to correlate the damage to existing structures to the displacement field of the landslide (e.g. Lateltin et al., 2005; Urciuoli \& Picarelli, 2008; Mansour et al., 2011; Picarelli, 2011; Palmisano et al., 2016). Rigorous solutions for landslide pressures were recently presented by Friedli et al. (2017) and Friedli (2018). It is less clear, however, what kind of design pressures should be used outside the sliding body, in the proximity of existing landslides, where no displacements have been observed. This question is relevant for both permanent landslides and one-time events, and of particular practical interest is the area just below the boundary of the landslide high-pressure compression zone. Intuitively, there should be a transition zone, within which high landslide pressures subside to the far-field (at rest) earth pressures in the stable slope. But how large is this transition zone and how fast do the earth pressures subside away from the slide?

This paper has been inspired by two practical cases in Switzerland. Fig. 1(a) shows the first case, with the recently mapped God Ruinas landslide in St Moritz. Observations over the past 5 years revealed an average yearly downhill displacement of a few millimetres, with a clear displacement field boundary. A large portion of the lower boundary correlates well with the flattening of the terrain below the

Manuscript received 9 November 2019; revised manuscript accepted 17 June 2020. Published online ahead of print 21 July 2020.

Discussion on this paper closes on 1 January 2022, for further details see p. ii.

Published with permission by the ICE under the CC-BY 4.0 license. (http://creativecommons.org/licenses/by/4.0/)

* Institute for Geotechnical Engineering, ETH Zurich, Zurich, Switzerland (Orcid:0000-0002-9566-8841). sliding body. It seems that, unlike the larger Brattas slide of St Moritz, which is constrained at the bottom by a rock outcrop (e.g. Schlüchter, 1988; Sterba et al., 2000), the God Ruinas sliding body was stopped by a more stable portion of the same soil mass with a milder slope inclination. The area with continuing downslope displacements has been included in a hazard map, imposing special construction regulations. What about the stable slope below this area, is it a safe place for a new excavation?

Similar boundary conditions can be observed in the second case, of a large historic Zürichberg landslide, which took place in 1770 in Zürich (Fig. 1(b)). A significant portion of the lower boundary of this slide correlates with the change of the inclination of the underlying bedrock from 15 to $10^{\circ}$. There are many buildings in the close proximity below this boundary, and possible effects of this proximity may include increased pressures on the existing structures. This becomes particularly important when a building in this area has to be replaced by a new one. What is the magnitude of earth pressure to be used in such a case for design of both the excavation and the structure?

Understanding the mechanism of the downhill pressure transfer within the stable part of the slope below the landslide is critical for finding the answers to these questions. The goal of this paper is to propose such a mechanism and to determine dimensions of the 'landslide influence zone' below the landslide and the lateral earth pressures within it, providing some insights for design considerations.

To achieve this goal, a bilinear slope will be considered (Fig. 2), with inclinations $\alpha_{\mathrm{s}}$ and $\alpha_{\mathrm{u}}\left(\alpha_{\mathrm{s}}<\alpha_{\mathrm{u}}\right)$ of its stable lower and unstable upper portions, respectively. In both the portions, at the depth $H$ below the surface there is a slope-parallel weak layer (or a weaker soil-rock interface) of thickness $d(d \ll H)$. The phreatic surface is also parallel to the slope, located at the depth $H_{\mathrm{w}}$ above the weak layer. The post-failure behaviour of the weak layer is described by the residual effective angle of internal friction $\phi_{\mathrm{r}}^{\prime}$. The shear strength of the sliding layer is characterised by the effective angle of internal friction $\phi^{\prime}$.

In the stable portion of the slope, at the distance $L$ from the base of the steep portion, there is a structure, which is embedded below the weak layer (Fig. 2). Assuming that the 


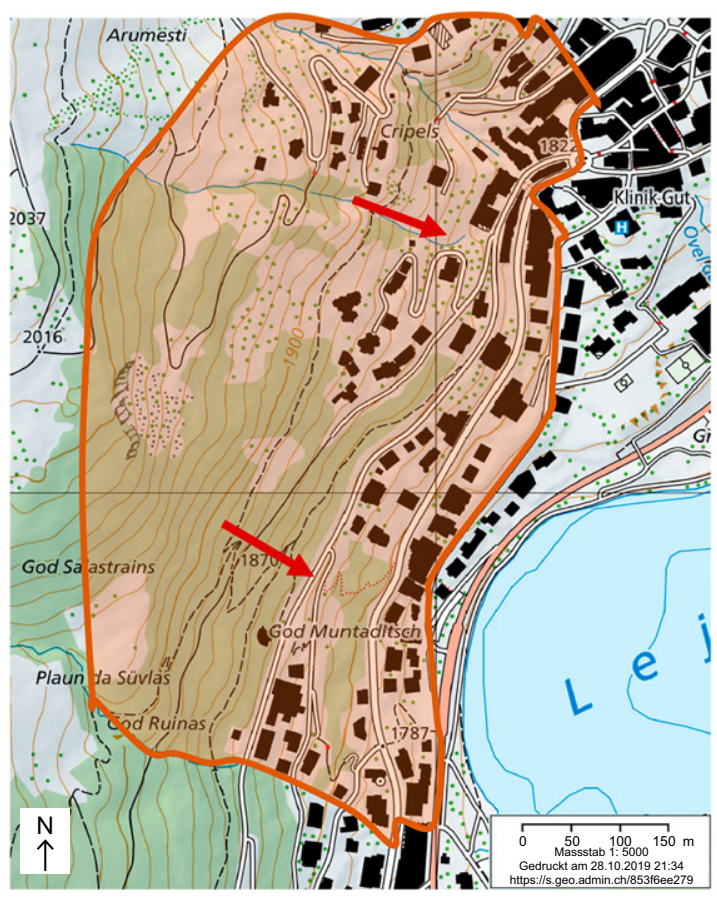

(a)

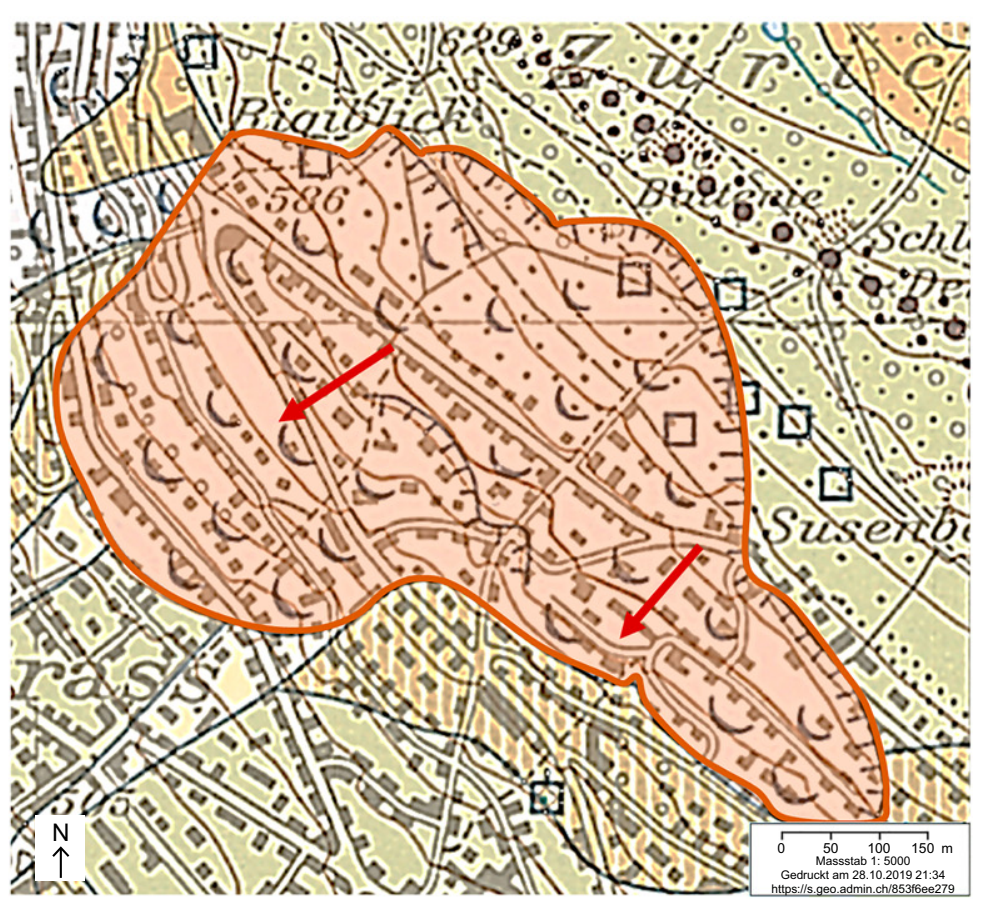

(b)

Fig. 1. (a) God Ruinas landslide, St Moritz, Switzerland (Swiss Federal Office of Topography, 2019). (b) Historic landslide on Zürichberg, Zürich, Switzerland. Shaded area shows the extent of instability. Arrows indicate downslope gradient. Note the large number of existing structures with potentially elevated earth pressures downhill from the lower boundary

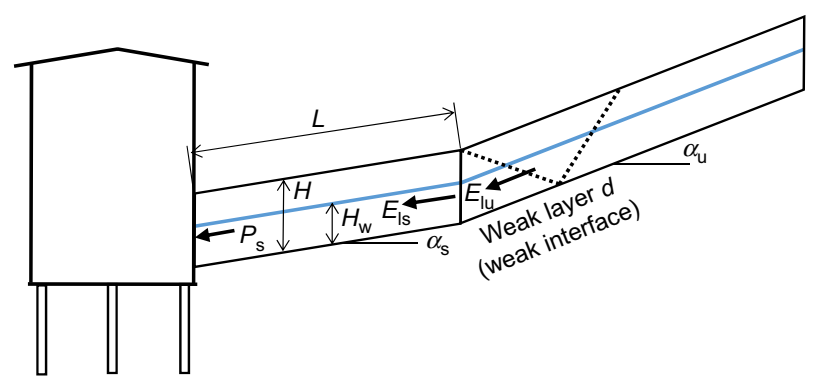

Fig. 2. Schematic layout of a structure embedded into a stable slope below a landslide

sliding layer has failed at the base of the unstable steep slope portion, the following are sought

(a) lateral (slope parallel) earth pressure acting on the embedded structure

(b) length of the landslide influence zone in the stable portion of the slope

(c) required excavation support within the landslide influence zone.

The following strategy has been adopted for this search in the sections below.

(a) Determine the landslide pressures acting at the boundary between unstable and stable parts of the slope (in the presence of the groundwater).

(b) Demonstrate the mechanism of progressive growth of the slip surface in the stable part of the slope, subjected to the action by the landslide pressure.

(c) Quantify the lateral earth pressures in the stable part of the slope (with and without embedded structure) using the process zone approach for the slip surface growth.

\section{EARTH PRESSURES AT THE FAILED BASE OF THE UNSTABLE SLOPE}

Consider a slope of inclination $\alpha$ with a slope-parallel weak layer and a slope-parallel groundwater flow (Fig. 3(a)). It is assumed that the total soil unit weight both below and above the phreatic surface is equal to $\gamma$. The landslide is only activated when the phreatic surface reaches the height $H_{\mathrm{w}}$, at which the gravitational shear stress exceeds the residual strength in the weak layer

$$
\tau_{g}=\gamma H \sin \alpha \cos \alpha \geq \tau_{\mathrm{r}}=\sigma_{\mathrm{n}}^{\prime} \tan \phi_{\mathrm{r}}^{\prime}=\left(\gamma H-\gamma_{\mathrm{w}} H_{\mathrm{w}}\right) \cos ^{2} \alpha \tan \phi_{\mathrm{r}}^{\prime}
$$

so that

$$
\frac{H_{\mathrm{w}}}{H}=\frac{\gamma}{\gamma_{\mathrm{w}}}(1-k) \leq 1 ; k=\frac{\tan \alpha}{\tan \phi_{\mathrm{r}}^{\prime}} \leq 1
$$

\section{Lower-bound solution}

For a case of a groundwater flow in the slope, Friedli et al. (2017) obtained a lower-bound limit analysis solution for the horizontal component of the ultimate landslide pressure acting on a vertical wall. The stress field in the landslide body (Fig. 3(a)) is separated into two regions: region 1 (dry) and region 2 (wet), above and below the phreatic surface, respectively. In the dry part the solution is given by the earth pressure coefficient $K_{\mathrm{lh}}^{\mathrm{d}}$ :

$$
\begin{aligned}
& \sigma_{x}^{\mathrm{d}}(z)=\gamma K_{\mathrm{lh}}^{\mathrm{d}} z \\
& K_{\mathrm{lh}}^{\mathrm{d}}=\frac{\cos ^{4} \alpha}{\cos ^{2} \phi^{\prime}}\left[1+\sqrt{1-\cos ^{2} \phi^{\prime}\left(1+\tan ^{2} \alpha\right)}\right]^{2}
\end{aligned}
$$

which happens to be identical to the corresponding upperbound solution (i.e. is exact). In the wet part, the total horizontal normal stress acting on a vertical plane can be 


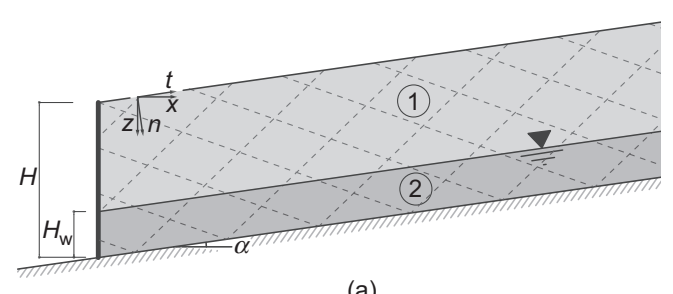

(a)

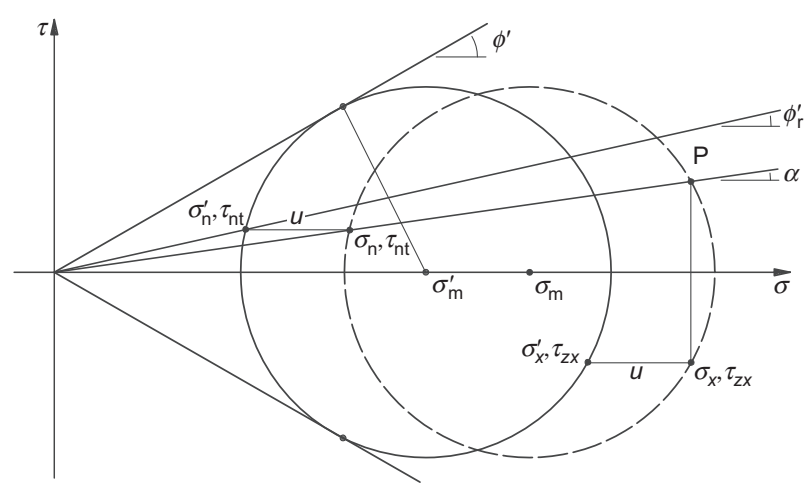

(b)

Fig. 3. Lower-bound solution for the earth pressures (after Friedli et al., 2017): (a) statically admissible stress state; (b) effective (solid line) and total (dashed line) Mohr circles for a stress state below phreatic surface

derived using the lower-bound analysis from Mohr circles in Fig. 3(b) (after Friedli et al., 2017)

$$
\sigma_{x}^{\mathrm{w}}(z)=\sigma_{\mathrm{m}} \frac{1+\sqrt{1-\left(1+\tan ^{2} \alpha\right)\left[1-\left(\sigma_{\mathrm{m}}^{\prime} / \sigma_{\mathrm{m}}\right)^{2} \sin ^{2} \phi^{\prime}\right]}}{1+\tan ^{2} \alpha}
$$

where the total mean stress is $\sigma_{\mathrm{m}}=\sigma_{\mathrm{m}}^{\prime}+u$; the water pressure is given by

$$
u=\gamma_{\mathrm{w}}\left[z-\left(H-H_{\mathrm{w}}\right)\right] \cos ^{2} \alpha
$$

and the mean effective stress is also derived from Mohr circles in Fig. 3(b)

$$
\sigma_{\mathrm{m}}^{\prime}=\sigma_{\mathrm{n}}^{\prime} \frac{1+\sqrt{1-\cos ^{2} \phi^{\prime}\left[1+\left(\tau_{\mathrm{nt}} / \sigma_{\mathrm{n}}^{\prime}\right)^{2}\right]}}{\cos ^{2} \phi^{\prime}}
$$

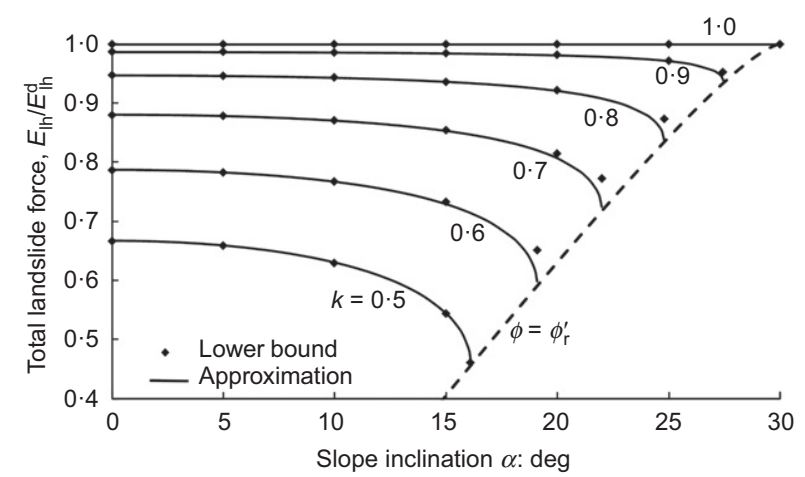

Fig. 4. Closed-form approximation by equation (17) of the total landslide force from equation (10)
The total normal stress $\sigma_{\mathrm{n}}$ and tangential shear stress $\tau_{\mathrm{nt}}$ are derived from the equilibrium equations

$$
\sigma_{\mathrm{n}}=\gamma z \cos ^{2} \alpha ; \quad \tau_{\mathrm{nt}}=\gamma z \sin \alpha \cos \alpha
$$

and normal effective stress $\sigma_{\mathrm{n}}^{\prime}$ is given by

$$
\sigma_{\mathrm{n}}^{\prime}=\sigma_{\mathrm{n}}-u=\left[\left(\gamma-\gamma_{\mathrm{w}}\right) z+\left(H-H_{\mathrm{w}}\right) \gamma_{\mathrm{w}}\right] \cos ^{2} \alpha
$$

The solution for the earth pressure in equation (5) is not exact, but Friedli et al. (2017) have shown that this lower-bound solution is very close to the corresponding upper-bound solution. The total landslide force acting on a vertical plane is determined by integrating equations (3) and (5) over the thickness of the dry and wet portions of the sliding layer, respectively

$$
E_{\mathrm{lh}}=\left.\frac{H-H_{\mathrm{w}}}{2} \sigma_{x}^{\mathrm{d}}\right|_{H-H_{\mathrm{w}}}+\int_{H-H_{\mathrm{w}}}^{H} \sigma_{x}^{\mathrm{w}}(z) \mathrm{d} z
$$

Closed-form approximation of the total landslide force

Although numerical integration of equation (10) is not complicated, it would be beneficial to obtain its closed-form approximation, both for practical applications and for subsequent derivations in this paper. This approximation can be achieved by linearising the depth dependency of the total lateral stresses in the wet portion $\sigma_{x}^{\mathrm{w}}(z)$

$$
E_{\mathrm{lh}}=\left.\frac{H-H_{\mathrm{w}}}{2} \sigma_{x}^{\mathrm{d}}\right|_{H-H_{\mathrm{w}}}+\frac{H_{\mathrm{w}}}{2}\left(\left.\sigma_{x}^{\mathrm{w}}\right|_{H-H_{\mathrm{w}}}+\left.\sigma_{x}^{\mathrm{w}}\right|_{H}\right)
$$

which can be rewritten using the fact that at the phreatic surface $\left.\sigma_{x}^{\mathrm{d}}\right|_{H-H_{\mathrm{w}}}=\left.\sigma_{x}^{\mathrm{w}}\right|_{H-H_{\mathrm{w}}}=\gamma K_{\mathrm{lh}}^{\mathrm{d}}\left(H-H_{\mathrm{w}}\right)$

$$
E_{\mathrm{lh}}=\frac{H}{2} \gamma K_{\mathrm{lh}}^{\mathrm{d}}\left(H-H_{\mathrm{w}}\right)+\left.\frac{H_{\mathrm{w}}}{2} \sigma_{x}^{\mathrm{w}}\right|_{H}
$$

where the total horizontal earth pressure at the weak layer boundary

$$
\left.\sigma_{x}^{\mathrm{w}}\right|_{H}=\gamma K_{\mathrm{lh}}^{\mathrm{w}}(k) H
$$

can be expressed using equations (2) and (5)-(9) by way of the total wet earth pressure coefficient at $z=H$

$$
\begin{aligned}
& K_{\mathrm{lh}}^{\mathrm{W}}(k) \\
& =a \cos ^{4} \alpha\left\{1+\sqrt{1-\left(1+\tan ^{2} \alpha\right)\left[1-\left(1-\frac{1-k}{a}\right)^{2} \sin ^{2} \phi^{\prime}\right]}\right\} \\
& a=\frac{k}{\cos ^{2} \phi^{\prime}}\left[1+\sqrt{1-\left(1+\frac{\tan ^{2} \alpha}{k^{2}}\right) \cos ^{2} \phi^{\prime}}\right]+1-k ; \quad k=\frac{\tan \alpha}{\tan \phi_{\mathrm{r}}^{\prime}}
\end{aligned}
$$

Limits on the value of parameter $k$ are imposed by equations (2) and the existence of the square root in equation (15)

$$
\max \left(1-\frac{\gamma_{\mathrm{w}}}{\gamma} ; \frac{\tan \alpha}{\tan \phi^{\prime}}\right) \leq k \leq 1
$$

Note that for $n=1$ (i.e. a dry slope) equation (14) gives the exact solution (4): $K_{\mathrm{lh}}^{\mathrm{w}}(1)=K_{\mathrm{lh}}^{\mathrm{d}}$, and the normalised approximate horizontal component of total landslide force acting on a vertical plane is determined by

$$
\frac{E_{\mathrm{lh}}}{E_{\mathrm{lh}}^{\mathrm{d}}}=1-\frac{\gamma}{\gamma_{\mathrm{w}}}(1-k)\left[1-\frac{K_{\mathrm{lh}}^{\mathrm{w}}(k)}{K_{\mathrm{lh}}^{\mathrm{d}}}\right] ; \quad E_{\mathrm{lh}}^{\mathrm{d}}=\frac{1}{2} K_{\mathrm{lh}}^{\mathrm{d}} \gamma H^{2}
$$


where $E_{\mathrm{lh}}^{\mathrm{d}}$ is the exact ultimate force for the entirely dry sliding layer. The corresponding effective earth pressures are given in Appendix 1.

For the case of $\phi^{\prime}=30^{\circ}$ and $\gamma=20 \mathrm{kN} / \mathrm{m}^{3}$, the approximation given by equation (17) is compared in Fig. 4 to the lower-bound solution integrated using equation (10) for the entire admissible ranges of the parameter $k$ and the slope inclination $\alpha$. For most practical cases, the relative error does not exceed $1 \%$. The maximum relative error can reach $8 \%$ for a practically improbable case of the residual shear strength of the weak layer being close to the peak shear strength of the sliding layer.

The calculated landslide force results from the failure of the slope when the phreatic surface rises to the critical value $H_{\mathrm{w}} / H=\gamma / \gamma_{\mathrm{w}}(1-k)$. Subsequent fluctuations of the phreatic surface are unlikely to cause an increase in the landslide pressure. Indeed, if the water level rises above the critical value, effective stresses in the sliding soil mass drop and the landslide force decreases (see Friedli et al. (2017)). On the other hand, if the water level drops, the shear resistance on the slip surface increases, preventing further movements, so that landslide pressures either remain constant or relax with time.

In spite of the fact that due to the groundwater flow the landslide pressure decreases (Fig. 4), its magnitude remains high (Friedli et al., 2017), in particular for lower slope inclinations in the steeper part. Such high pressures are likely to affect stresses in the stable portion of the slope below the landslide. The next section demonstrates the mechanism of the pressure transfer.

\section{PROGRESSIVE PROPAGATION OF THE SLIP SURFACE IN THE STABLE SLOPE}

The sliding of the soil mass often takes place along a narrow slip surface with reduced strength in which most of

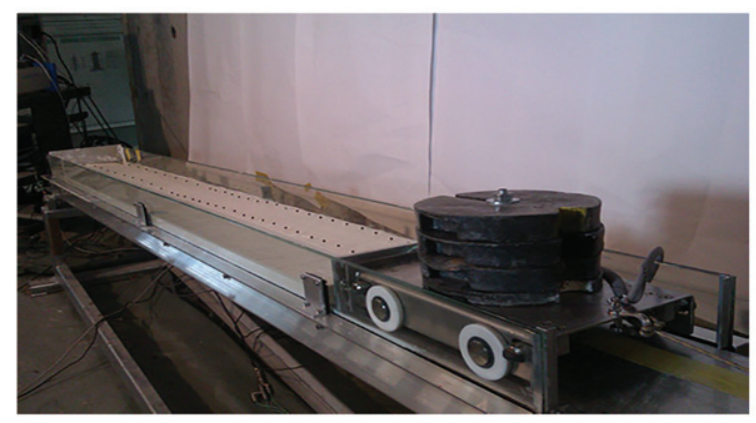

(a)

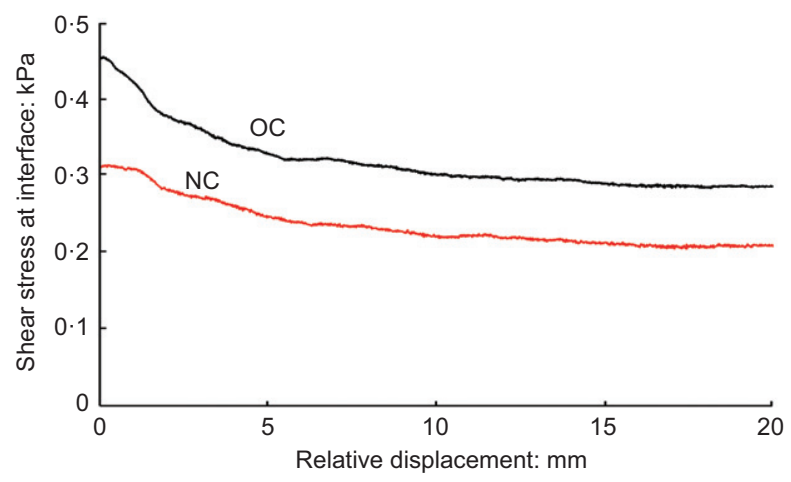

(c) the shear strains are localised (e.g. Bernander \& Olofsson, 1981). Numerous studies (e.g. Hansbo et al., 1985; Bernander et al., 1989; Wiberg et al., 1990; Dey et al., 2012; Locat et al., 2013) have treated progressive growth of slip surfaces within the finite-elements or finite-differences frameworks, without experimental validation of the proposed methodology. Puzrin et al. (2016) demonstrated that when the top of a stable slope is subjected to an increasing lateral earth pressure, this can cause propagation of a slip surface along a slope-parallel weak interface. The main results of this study are briefly summarised below. A layer of saturated kaolinite clay (4 cm thick) was consolidated in a $2 \mathrm{~m}$ long and $25 \mathrm{~cm}$ wide chute with steel bottom and glass walls (Fig. 5(a)). After consolidation, the chute was inclined by $10^{\circ}$ and a gradually increasing static force was applied on top of the sliding layer with the help of a miniature 'bulldozer'. The force and displacements of the bulldozer were measured using a set of three load cells, and by a laser displacement sensor, respectively. The evolving length of the slip surface at the weaker contact between the clay layer and the steel bottom of the chute was detected using a fibre optic strain sensing technology. Two optical fibres were installed parallel to the slope in the sliding layer with the help of micro anchors, spaced at $1 \mathrm{~cm}$ distance from each other, resulting in 400 individual high-precision strain gauges along the slope. The cables were pre-tensioned and the compressive strain distribution in the sliding layer was measured for different positions of the bulldozer, resulting in different values of the applied force (Fig. 5(b)). The tip of the fully softened slip surface correlates with the end of the straight portion of the strain profile in Fig. 5(b), because the lateral force decreases linearly in the sliding layer above the propagated slip surface.

Independent interface shear tests showed softening behaviour at the contact between the sliding layer and the steel of the chute for both normally and lightly overconsolidated

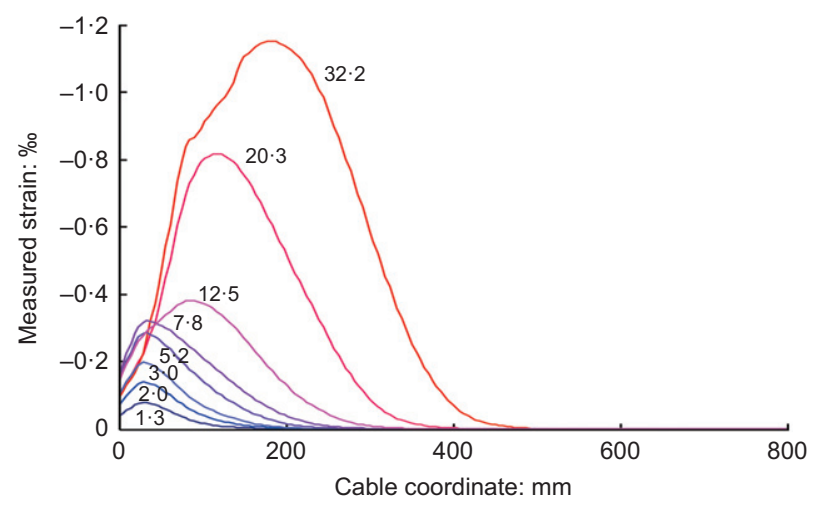

(b)

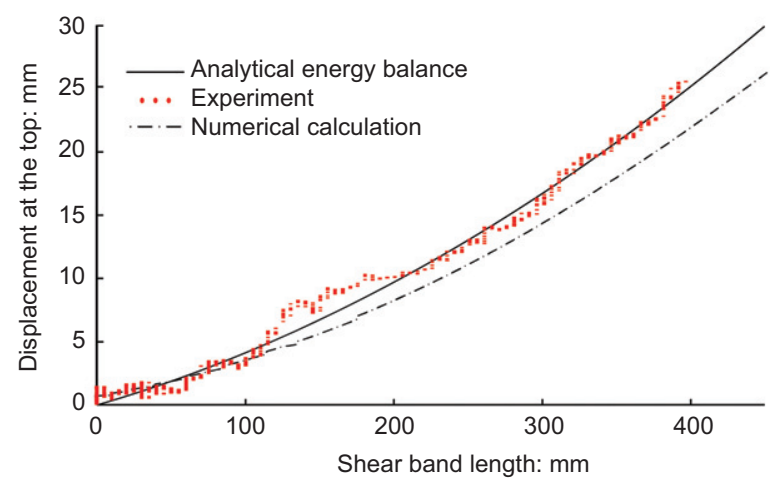

(d)

Fig. 5. Slip surface growth in a stable $\left(\tau_{g}<\tau_{\mathrm{r}}\right)$ kaolinite clay slope (after Puzrin et al., 2016): (a) experimental set-up; (b) evolution of measured compressive strains in the sliding layer for different levels of applied force $(\mathrm{N})$; (c) strain softening in the interface tests on normally (NC) and overconsolidated (OC) clay; (d) evolution of the shear band length 
(overconsolidation ratio, OCR $=3$ ) clays $($ Fig. $5(\mathrm{c})$ ). These softening curves have been used directly as a constitutive relationship for the interface behaviour in Abaqus. Numerical simulation of the evolution of the length of the slip surface propagating progressively at the bottom of an elastic layer (inclined by $10^{\circ}$ ) is shown by a dashed line in Fig. 5(d) as a function of the bulldozer displacements. Analytical predictions (solid line in Fig. 5(d)) were obtained using the simplified energy balance approach (Palmer \& Rice, 1973; Viesca \& Rice, 2012; Puzrin et al., 2016). Both analytical and numerical predictions fit the measured approximate shear band length (data points in Fig. 5(d)) reasonably well, validating the proposed mechanism of the progressive slip surface growth in the stable slope. However, in order to determine the length of the landslide influence zone it is not sufficient to know the length of the slip surface, because the earth pressures can still be elevated downhill from its tip. In the next section an approach is formulated allowing derivation of the stress and displacement fields in the slope below the tip of the slip surface.

\section{PROCESS ZONE APPROACH TO THE GROWTH OF THE SLIP SURFACE}

In this section the boundary value problem is formulated of progressive downhill growth of the slip surface into the stable portion $\left(\alpha_{\mathrm{s}}\right)$ of the plane-strain bilinear slope in Fig. 2. The slip surface grows within the weak layer of thickness, $d$ (or along a weak interface), located at the depth, $H$, with the soil above it designated as the sliding layer. This propagation is driven by the increasing slope-parallel lateral pressure from the unstable upper part of inclination $\alpha_{\mathrm{u}}\left(\alpha_{\mathrm{s}}<\alpha_{\mathrm{u}}\right)$. After the upper part of the slope fails, the landslide force reaches its ultimate value $E_{\mathrm{lu}}=E_{\mathrm{lh}} / \cos \alpha_{\mathrm{u}}$, where $E_{\mathrm{lh}}$ is its horizontal component defined from equation (17) for $\alpha=\alpha_{\mathrm{u}}$. For the analysis of the slip surface growth in the stable part of the slope $\alpha_{\mathrm{s}}$, the slope-parallel component $E_{\mathrm{ls}}$ of the force $E_{\mathrm{lu}}$ is needed

$$
E_{\mathrm{ls}}=E_{\mathrm{lu}} \cos \left(\alpha_{\mathrm{u}}-\alpha_{\mathrm{s}}\right)=E_{\mathrm{lh}} \cos \alpha_{\mathrm{s}}\left(1+\tan \alpha_{\mathrm{s}} \tan \alpha_{\mathrm{u}}\right)
$$

Derivation of the stress and displacement fields in the weak layer below the tip of the slip surface is possible within the framework of the process zone approach to the slip surface propagation (Zhang et al., 2015). Within this framework, the partially softened process zone is located in the weak layer between the slip surface (i.e. the fully softened zone where the shear strength has dropped to its residual value) and the semi-infinite zone of elastic shearing (Fig. 6). The pre-failure mechanical behaviour of the weak layer is assumed as linear elastic, characterised by the shear modulus $G$ (Fig. 7). The post-failure behaviour is plastic with linear softening, with the shear strength dropping over the characteristic shear strain $\gamma_{\mathrm{r}}$ from its peak value $\tau_{\mathrm{p}}$ to the residual value $\tau_{\mathrm{r}}$. Progressive growth of the slip surface is assumed to be sufficiently slow (drained) for the shear strength to be characterised by the peak $\phi_{\mathrm{p}}^{\prime}$ and residual $\phi_{\mathrm{r}}^{\prime}$ values of the effective angle of internal friction, respectively. The mechanical behaviour of the sliding layer is linear elasticperfectly plastic, characterised by the plane-strain elastic modulus $E^{\prime}$ and the effective angle of internal friction $\phi^{\prime}$. The at-rest earth pressure coefficient in the far field of the stable portion with the inclination $\alpha_{\mathrm{s}}$ is $K_{0}$.

In contrast to equation (1), because the slope $\alpha_{\mathrm{s}}$ is stable, the gravitational shear stress $\tau_{g}$ is smaller than the residual strength in the weak layer $\tau_{\mathrm{r}}$

$$
\begin{gathered}
\tau_{g}=\gamma H \sin \alpha_{\mathrm{s}} \cos \alpha_{\mathrm{s}}<\tau_{\mathrm{r}}=\sigma_{\mathrm{n}}^{\prime} \tan \phi_{\mathrm{r}}^{\prime}=\gamma H k \cos ^{2} \alpha_{\mathrm{s}} \tan \phi_{\mathrm{r}}^{\prime} \\
\frac{\gamma H-\gamma_{\mathrm{w}} H_{\mathrm{w}}}{\gamma H}=k=\frac{\tan \alpha_{\mathrm{u}}}{\tan \phi_{\mathrm{r}}^{\prime}} \leq 1
\end{gathered}
$$

and the lateral force $P$ in the fully softened zone decreases downslope (Fig. 6). In the process zone, the shear stress increases downslope from residual strength $\tau_{\mathrm{r}}$ to the peak strength $\tau_{\mathrm{p}}$

$$
\begin{gathered}
\tau_{\mathrm{p}}=s \tau_{\mathrm{r}}=\gamma H k s \cos ^{2} \alpha_{\mathrm{s}} \tan \phi_{\mathrm{r}}^{\prime} ; \quad s=\frac{\tan \phi_{\mathrm{p}}^{\prime}}{\tan \phi_{\mathrm{r}}^{\prime}} \\
\tau_{\mathrm{p}}-\tau_{\mathrm{r}}=\gamma H k(s-1) \cos ^{2} \alpha_{\mathrm{s}} \tan \phi_{\mathrm{r}}^{\prime}
\end{gathered}
$$

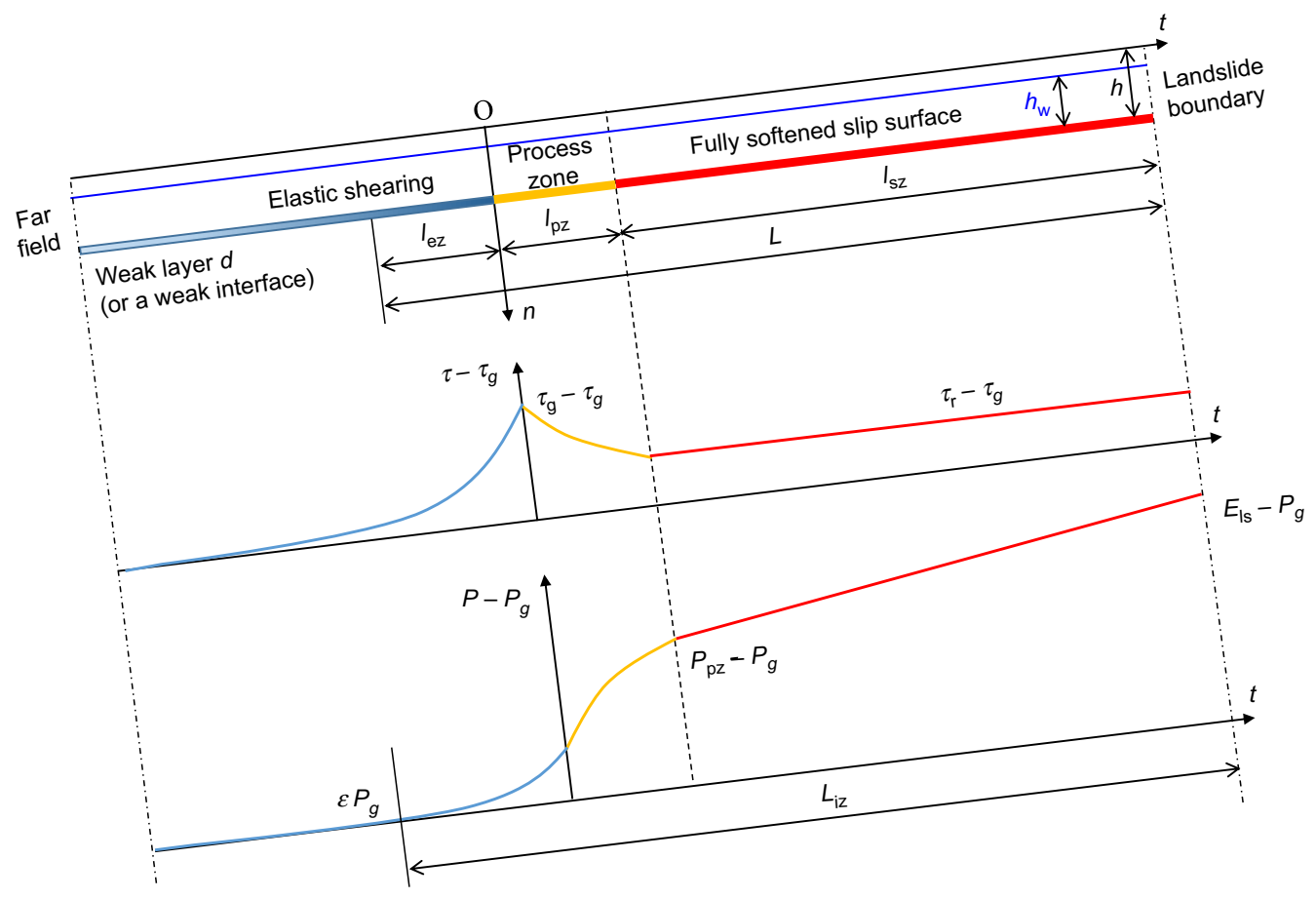

Fig. 6. Process zone approach to the slip surface growth in a stable slope 


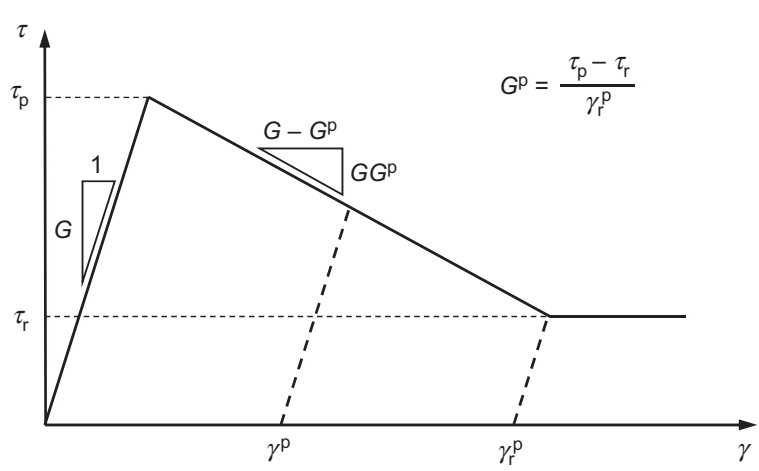

Fig. 7. Shear stress-strain behaviour of the weak layer

In the elastic shear zone, the shear stress in the weak layer gradually decreases back to the gravitational shear stress $\tau_{g}$, while the slope-parallel force in the sliding layer goes back to the far-field value $P_{g}$ (Fig. 6)

$$
\begin{aligned}
& P_{g}=\frac{1}{2}\left[K_{0}\left(\gamma H^{2}-\gamma_{\mathrm{w}} H_{\mathrm{w}}^{2}\right)+\gamma_{\mathrm{w}} H_{\mathrm{w}}^{2}\right] \cos ^{3} \alpha_{\mathrm{s}}=\frac{1}{2} K_{g} \gamma H^{2} \\
& K_{g}=K_{0}\left[1+\left(\frac{1}{K_{0}}-1\right)(1-k)^{2} \frac{\gamma}{\gamma_{\mathrm{w}}}\right] \cos ^{3} \alpha_{\mathrm{s}}
\end{aligned}
$$

For convenience with later algebra, the origin $\mathrm{O}$ of the Cartesian coordinates system in Fig. 6 has been placed at the interface between the process zone and the region of purely elastic deformations. The analysis will use 'net' values of elastic $\delta^{\mathrm{e}}$ and plastic $\delta^{\mathrm{p}}$ components of displacements and shear stress $\tau$ across the weak layer and lateral force $P$ in the sliding layer with respect to their far-field downhill values in an infinite slope $\alpha_{\mathrm{s}}$

$$
\Delta \delta^{\mathrm{e}}=\delta^{\mathrm{e}}-\delta_{g} ; \Delta \delta^{\mathrm{p}}=\delta^{\mathrm{p}} ; \Delta P=P-P_{g} ; \Delta \tau=\tau-\tau_{g}
$$

where $\delta_{g}=G d \tau_{g}$ is the far-field displacement in the weak layer; $\tau_{g}$ and $P_{g}$ are defined from equations (19) and (21), respectively. Defining the shear stress ratio $r$ as

$$
r=\frac{\tau_{g}-\tau_{\mathrm{r}}}{\tau_{\mathrm{p}}-\tau_{\mathrm{r}}}=\frac{\left(\tan \alpha_{s} / k \tan \phi_{\mathrm{r}}^{\prime}\right)-1}{s-1}=\frac{\left(\tan \alpha_{\mathrm{s}} / \tan \alpha_{\mathrm{u}}\right)-1}{s-1}
$$

leads to the following expressions for the 'net' peak and residual strength

$$
\Delta \tau_{\mathrm{p}}=\tau_{\mathrm{p}}-\tau_{g}=(1-r)\left(\tau_{\mathrm{p}}-\tau_{\mathrm{r}}\right) ; \quad \Delta \tau_{\mathrm{r}}=\tau_{\mathrm{r}}-\tau_{g}=-r\left(\tau_{\mathrm{p}}-\tau_{\mathrm{r}}\right)
$$

Formulation of the boundary value problem is based on: (a) the equilibrium equation of the sliding layer; $(b)$ the constitutive equation for the sliding layer; and (c) the compatibility between displacements $\Delta v$ within the sliding layer and the net displacements $\Delta \delta$ across the weak layer
(a) $\frac{\mathrm{d} \Delta P}{\mathrm{~d} t}=\Delta \tau ;$
(b) $\frac{\mathrm{d} \Delta v}{\mathrm{~d} t}=\frac{\Delta P}{E^{\prime} h}$
(c) $\Delta u=\Delta \delta=\Delta \delta^{\mathrm{e}}+\Delta \delta^{\mathrm{p}}=\frac{\Delta \tau}{G} d+\Delta \delta^{\mathrm{p}}$

where $h=H \cos \alpha_{\mathrm{s}}$ is the thickness of the sliding layer and $d$ is the thickness of the weak layer.

Combining equations (25) produces the governing differential equations
(a) $\frac{\mathrm{d}^{2} \Delta P}{\mathrm{~d} t^{2}}=\frac{G}{E^{\prime} h d} \Delta P$;
(b) $\frac{\mathrm{d}^{2} \Delta \tau}{\mathrm{d} t^{2}} \frac{d}{G}+\frac{\mathrm{d}^{2} \Delta \delta^{\mathrm{p}}}{\mathrm{d} t^{2}}=\frac{\Delta \tau}{E^{\prime} h}$
(c) $\frac{\mathrm{d} \Delta P}{\mathrm{~d} t}=\Delta \tau_{\mathrm{r}}$

for $(a)$ the zone of elastic shearing $\left(\Delta \delta^{\mathrm{p}}=0\right) ;(b)$ the process zone $\left(\Delta \tau=\Delta \tau\left(\Delta \delta^{\mathrm{p}}\right)\right)$; and (c) the fully softened zone ( $\Delta \tau=\Delta \tau_{\mathrm{r}}=$ const), respectively. The boundary value problem formulation for the process zone approach is completed by prescribing boundary conditions, which are going to be different depending on the presence of the structure embedded into the stable part of the slope.

\section{EARTH PRESSURES ACTING ON THE EMBEDDED STRUCTURE}

Consider a structure, embedded below the weak layer at the distance $L$ from the top of the stable portion of the slope (Fig. 2). The present goal is to find the slope-parallel earth pressure $P_{\mathrm{s}}$ acting on the structure. The lengths of the elastic zone $l_{\mathrm{ez}}$, process zone $l_{\mathrm{pz}}$ and fully softened zone $l_{\mathrm{sz}}$ are not known and will have to be determined by solving differential equations (26) together with the corresponding boundary conditions and equation

$$
L=l_{\mathrm{ez}}+l_{\mathrm{pz}}+l_{\mathrm{sz}}
$$

\section{Elastic shearing zone}

Earth pressures in the elastic zone are calculated by solving the first equation (26) with the boundary conditions (of peak shear strength at the upper boundary and zero displacement at the structure)

$$
t=0: \frac{\mathrm{d} \Delta P}{\mathrm{~d} t}=\Delta \tau_{\mathrm{p}} ; \quad t=-l_{\mathrm{ez}}: \frac{\mathrm{d} \Delta P}{\mathrm{~d} t}=\Delta \tau=G \frac{\Delta \delta^{\mathrm{e}}}{d}=0
$$

The resulting solution is given by

$$
\Delta P=\Delta \tau_{\mathrm{p}} l_{\mathrm{e}} \frac{\cosh \left[\left(t+l_{\mathrm{ez}}\right) / l_{\mathrm{e}}\right]}{\sinh \left[l_{\mathrm{ez}} / l_{\mathrm{e}}\right]}
$$

where

$$
l_{\mathrm{e}}=\sqrt{\frac{E^{\prime} h d}{G}}
$$

is the characteristic elastic length. The net earth pressure acting on the structure at $t=-l_{\mathrm{ez}}$

$$
\Delta P_{\mathrm{s}}=\frac{\Delta \tau_{\mathrm{p}} l_{\mathrm{e}}}{\sinh \left[l_{\mathrm{ez}} / l_{\mathrm{e}}\right]}=\frac{(1-r)\left(\tau_{\mathrm{p}}-\tau_{\mathrm{r}}\right) l_{\mathrm{e}}}{\sinh \left[l_{\mathrm{ez}} / l_{\mathrm{e}}\right]}
$$

can be determined after we find the length of the elastic zone $l_{\text {ez. }}$. To achieve this we first need to determine the length of the process zone.

\section{Process zone}

Finding the length of the process zone $l_{\mathrm{pz}}$, requires knowledge of the shear strength softening function. Assuming the following linear expression (Fig. 7):

$$
\tau=\tau_{\mathrm{p}}+\left(\tau_{\mathrm{r}}-\tau_{\mathrm{p}}\right) \frac{\gamma^{\mathrm{p}}}{\gamma_{\mathrm{r}}^{\mathrm{p}}}=\tau_{\mathrm{p}}-G^{\mathrm{p}} \gamma^{\mathrm{p}} ; \quad G^{\mathrm{p}}=\frac{\tau_{\mathrm{p}}-\tau_{\mathrm{r}}}{\gamma_{\mathrm{r}}^{\mathrm{p}}}
$$

and using definitions (22)-(24), it is possible to write

$$
\Delta \tau=\left(\tau_{\mathrm{p}}-\tau_{\mathrm{r}}\right)\left(1-r-\bar{\delta}^{\mathrm{p}}\right)
$$

where $\delta^{\mathrm{p}}=\gamma^{\mathrm{p}} d$ and $\bar{\delta}^{\mathrm{p}}=\delta^{\mathrm{p}} / \delta_{\mathrm{r}}^{\mathrm{p}}=\gamma^{\mathrm{p}} / \gamma_{\mathrm{r}}^{\mathrm{p}}$ are the actual and 
normalised plastic displacements, respectively. Substitution of equation (33) into the second equation (26) gives

$$
\frac{\mathrm{d}^{2} \bar{\delta}^{\mathrm{p}}}{\mathrm{d} \bar{t}^{2}}=\frac{1-r-\bar{\delta}^{\mathrm{p}}}{\beta^{2}}
$$

where $\bar{t}=t / l_{\mathrm{u}}$ is the normalised coordinate

$$
\beta^{2}=1-\frac{G^{\mathrm{p}}}{G}=1-\left(\frac{l_{\mathrm{e}}}{l_{\mathrm{u}}}\right)^{2} \text { and } l_{\mathrm{u}}=\sqrt{\frac{E^{\prime} h \delta_{\mathrm{r}}^{\mathrm{p}}}{\tau_{\mathrm{p}}-\tau_{\mathrm{r}}}}=\sqrt{\frac{E^{\prime} h d}{G^{\mathrm{p}}}}
$$

are the stiffness parameter and the characteristic length, respectively.

Substitution of equation (33) into the third (c) and second (b) equations (25) results in

$$
\frac{\mathrm{d} \bar{\delta}^{\mathrm{p}}}{\mathrm{d} \bar{t}}=\frac{\Delta \bar{P}}{\beta^{2}}
$$

where $\Delta \bar{P}=\Delta P /\left(\tau_{\mathrm{p}}-\tau_{\mathrm{r}}\right) l_{\mathrm{u}}$ is the normalised net lateral force. This allows the boundary conditions at $t=0$ to be formulated

$$
\bar{\delta}^{\mathrm{p}}=0 ; \quad \frac{\mathrm{d} \bar{\delta}^{\mathrm{p}}}{\mathrm{d} \bar{t}}=\left.\frac{1}{\beta^{2}} \quad \Delta \bar{P}\right|_{\bar{t}=0}=(1-r) \frac{\sqrt{1-\beta^{2}}}{\beta^{2}} \operatorname{coth} \frac{l_{\mathrm{ez}}}{l_{\mathrm{e}}}
$$

where the second condition is obtained from equilibrium at the boundary with the elastic shearing zone $t=0$, where the net lateral force is defined from equation (29). Solving equation (34) with boundary conditions (37) gives

$$
\bar{\delta}^{\mathrm{p}}=(1-r)\left(1-\frac{b}{\beta} \sin \frac{\omega_{\mathrm{b}}-\bar{t}}{\beta}\right)
$$

where

$$
\omega_{\mathrm{b}}=\beta \arcsin \frac{\beta}{b} ; \quad b=\sqrt{\beta^{2}+\left(1-\beta^{2}\right) \operatorname{coth}^{2} \frac{l_{\mathrm{ez}}}{l_{\mathrm{e}}}}
$$

The normalised net lateral forces in the process zone are calculated by substituting equation (38) into (36)

$$
\Delta \bar{P}=b(1-r) \cos \frac{\omega_{\mathrm{b}}-\bar{t}}{\beta}
$$

The length of the process zone is found from equation (38) and the condition that at the boundary with the fully softened zone $t=l_{\mathrm{pz}}$, the shear strength dropped to its residual value - that is, the plastic displacement reached $\delta_{\mathrm{r}}^{\mathrm{p}}$, so that $\bar{\delta}^{\mathrm{p}}=1$

$$
l_{\mathrm{pz}}=l_{\mathrm{u}} \beta\left[\arcsin \frac{\beta}{b}+\arcsin \frac{\beta r}{b(1-r)}\right]
$$

Note that through the second equation (39), the length of the process zone $l_{\mathrm{pz}}(b)$ is a function of the length of the elastic zone $l_{\text {ez. }}$. The final step in finding this elastic zone requires knowledge of the length of the fully softened zone.

\section{Fully softened zone}

The length of the fully softened zone $l_{\mathrm{sz}}$ can be calculated by solving the third equation (26) with known earth pressure boundary conditions at both tips of the fully softened zone

$$
l_{\mathrm{sz}}=\frac{\Delta P_{\mathrm{ls}}-\Delta P_{\mathrm{pz}}}{\Delta \tau_{\mathrm{r}}}=-\frac{\Delta P_{\mathrm{ls}}-\Delta P_{\mathrm{pz}}}{r\left(\tau_{\mathrm{p}}-\tau_{\mathrm{r}}\right)}
$$

where the force at the top of the stable slope $\Delta P_{\mathrm{ls}}=E_{\mathrm{ls}}-P_{g}$ is the net landslide force determined from equations (18) and (21), while the net force $\Delta P_{\mathrm{pz}}$ at the boundary of the process zone with the fully softened zone $t=l_{\mathrm{pz}}$ is calculated by substituting equation (41) into (40)

$$
\Delta P_{\mathrm{pz}}=\left(\tau_{\mathrm{p}}-\tau_{\mathrm{r}}\right) l_{\mathrm{u}} \sqrt{b^{2}(1-r)^{2}-\beta^{2} r^{2}}
$$

so that

$$
l_{\mathrm{sz}}=\frac{E_{\mathrm{ls}}-P_{g}}{-r\left(\tau_{\mathrm{p}}-\tau_{\mathrm{r}}\right)}-l_{\mathrm{u}} \sqrt{b^{2}(1 / r-1)^{2}-\beta^{2}}
$$

Note that the length of the fully softened zone $l_{\mathrm{sz}}(b)$ is also a function of the length of the elastic zone $l_{\mathrm{ez}}$, through the second equation (39).

\section{Earth pressure on embedded structure}

Substituting $l_{\mathrm{pz}}(b)$ and $l_{\mathrm{sz}}(b)$ from equations (41) and (44), respectively, into equation (27) and normalising with respect to $l_{\mathrm{u}}$ gives

$$
\bar{L}=\hat{l}_{\mathrm{ez}} \sqrt{1-\beta^{2}}+f\left[\beta, r, b\left(\hat{l}_{\mathrm{ez}}\right)\right]+\frac{1}{-r}\left(\bar{E}_{\mathrm{ls}}-\bar{P}_{g}\right)
$$

where

$$
\begin{aligned}
& f(\beta, r, b)=\beta\left[\arcsin \frac{\beta}{b}+\arcsin \frac{\beta r}{b(1-r)}\right] \\
& -\sqrt{b^{2}(1 / r-1)^{2}-\beta^{2}} \\
& b=\sqrt{\beta^{2}+\left(1-\beta^{2}\right) \operatorname{coth}^{2} \hat{l}_{\mathrm{ez}}} \\
& \hat{l}_{\mathrm{ez}}=\frac{l_{\mathrm{ez}}}{l_{\mathrm{e}}} \quad \bar{L}=\frac{L}{l_{\mathrm{u}}} ; l_{\mathrm{e}}=\sqrt{\frac{E^{\prime} h d}{G}} \\
& r=\frac{\tan \alpha_{\mathrm{s}} / \tan \alpha_{\mathrm{u}}-1}{s-1} ; \\
& \beta=\sqrt{1-\frac{G^{\mathrm{p}}}{G}} ; \quad l_{\mathrm{u}}=\sqrt{\frac{E^{\prime} h d}{G^{\mathrm{p}}}} ; \quad h=H \cos \alpha_{\mathrm{s}}
\end{aligned}
$$

The normalised lateral forces $\bar{E}_{\mathrm{ls}}$ and $\bar{P}_{g}$ :

$$
\bar{E}_{\mathrm{ls}}=\frac{E_{\mathrm{ls}}}{\left(\tau_{\mathrm{p}}-\tau_{\mathrm{r}}\right) l_{\mathrm{u}}} ; \quad \bar{P}_{g}=\frac{P_{g}}{\left(\tau_{\mathrm{p}}-\tau_{\mathrm{r}}\right) l_{\mathrm{u}}}
$$

are determined using equations (17), (18) and (21)

$$
\begin{aligned}
& \bar{E}_{\mathrm{ls}}=\frac{K_{\mathrm{lh}}^{\mathrm{d}} H}{2 l_{\mathrm{u}}(s-1)}\left[1-\frac{\gamma}{\gamma_{\mathrm{w}}}(1-k)\left(1-\frac{K_{\mathrm{lh}}^{\mathrm{w}}}{K_{\mathrm{lh}}^{\mathrm{d}}}\right)\right] \frac{1+\tan \alpha_{\mathrm{s}} \tan \alpha_{\mathrm{u}}}{\cos \alpha_{\mathrm{s}} \tan \alpha_{\mathrm{u}}} \\
& \bar{P}_{g}=\frac{K_{0} H}{2 l_{\mathrm{u}}(s-1)}\left[1+\left(\frac{1}{K_{0}}-1\right)(1-k)^{2} \frac{\gamma}{\gamma_{\mathrm{w}}}\right] \frac{\cos \alpha_{\mathrm{s}}}{\tan \alpha_{\mathrm{u}}} ; \quad k=\frac{\tan \alpha_{\mathrm{u}}}{\tan \phi_{\mathrm{r}}^{\prime}}
\end{aligned}
$$

where

$$
\begin{aligned}
& K_{\mathrm{lh}}^{\mathrm{d}}=\frac{1}{\cos ^{2} \phi^{\prime}}\left[\frac{1+\sqrt{1-\cos ^{2} \phi^{\prime}\left(1+\tan ^{2} \alpha_{\mathrm{u}}\right)}}{1+\tan ^{2} \alpha_{\mathrm{u}}}\right]^{2} \\
& K_{\mathrm{lh}}^{\mathrm{w}}(k)=a \frac{1+\sqrt{1-\left(1+\tan ^{2} \alpha_{\mathrm{u}}\right)\left(1-\{1-[(1-k) / a]\}^{2} \sin ^{2} \phi^{\prime}\right)}}{\left(1+\tan ^{2} \alpha_{\mathrm{u}}\right)^{2}} \\
& a=\frac{k}{\cos ^{2} \phi^{\prime}}\left[1+\sqrt{1-\left(1+\frac{\tan ^{2} \alpha_{\mathrm{u}}}{k^{2}}\right) \cos ^{2} \phi^{\prime}}\right]+1-k
\end{aligned}
$$


are the 'dry' and 'wet' landslide earth pressure coefficients from equations (4) and (14).

Resolving equation (45) with respect to $\hat{l}_{\mathrm{ez}}$, substituting the result into equation (31) and normalising it by the total far-field (at rest) lateral force $P_{g}$ from equation (21), gives the normalised total force $P_{\mathrm{s}} / P_{g}$ acting on the structure embedded at distance $L$ from the top of the stable slope

$$
\frac{P_{\mathrm{s}}}{P_{g}}=1+\frac{\Delta \tau_{\mathrm{p}} l_{\mathrm{e}}}{P_{g} \sinh \left[\hat{l}_{\mathrm{ez}}(\bar{L})\right]}=1+\frac{(1-r) \sqrt{1-\beta^{2}}}{\bar{P}_{g} \sinh \left[\hat{l}_{\mathrm{ez}}(\bar{L})\right]}
$$

For special cases of smaller landslide pressures and structures close to the landslide boundary, where the slip surface and process zone cannot fully develop, the earth pressures on the structures are derived in Appendices 2 and 3, respectively. Note that the normalised total forces depend on elastic properties by way of parameter $\beta$.

\section{Parametric study}

In the general case of all three zones fully developed, total lateral forces on the embedded structure are defined by equations (45)-(51). For smaller landslide pressures or closer distance to the landslide, lateral forces on the embedded structure are defined by equations (70), (73) and (74) in Appendix 2. These expressions depend on a large number of soil and geometric parameters. The parametric study presented below is limited to highlighting the importance of the slope inclination in the unstable $\alpha_{\mathrm{u}}$ and stable $\alpha_{\mathrm{s}}$ parts of the slope, as well as of the phreatic surface height above the slip surface: $H_{\mathrm{w}} / H=\gamma / \gamma_{\mathrm{w}}(1-k) \leq 1$. Fig. 8 shows the normalised total lateral force $P_{\mathrm{s}} / P_{g}$ on the structure embedded at the normalised distance $L / H$ downslope from the landslide, for two slope inclinations of the unstable part $\alpha_{\mathrm{u}}=15$ and $20^{\circ}$; four slope inclinations of the stable part $\alpha_{\mathrm{s}}=0,5,8$ and $10^{\circ}$; and two groundwater levels $H_{\mathrm{w}} / H=$ 0.0 and $0.6(k=1.0$ and 0.7$)$. For simplicity, it is assumed that $l_{\mathrm{u}} \approx H$, with remaining parameters: $\phi^{\prime}=30^{\circ} ; \gamma=$ $20 \mathrm{kN} / \mathrm{m}^{3} ; \gamma_{\mathrm{w}}=10 \mathrm{kN} / \mathrm{m}^{3} ; \beta=0.9 ; s=2 ; K_{0}=0.5$.

The groundwater table enters the solution in Fig. 8 through parameter $k$. It follows that a steeper inclination of the unstable part of the slope and a higher groundwater table lead to a decrease in the pressures acting on the structure (due to smaller landslide pressures), while a steeper inclination of the stable part of the slope results in an increase in the pressures acting on the structure (due to a higher gravitational shear stress).

\section{LANDSLIDE INFLUENCE ZONE}

When slope displacements are not hindered by an embedded structure, the goal is to determine the portion $L_{\mathrm{iz}}$ of the stable slope, which is affected by the net earth pressures exceeding a certain percentage $\varepsilon$ (e.g. 5\%) of the far-field lateral force $P_{g}$ (Fig. 6):

$$
L_{\mathrm{iz}}\left(\Delta P>\varepsilon P_{g}\right)=l_{\mathrm{ez}}+l_{\mathrm{pz}}+l_{\mathrm{sz}}
$$
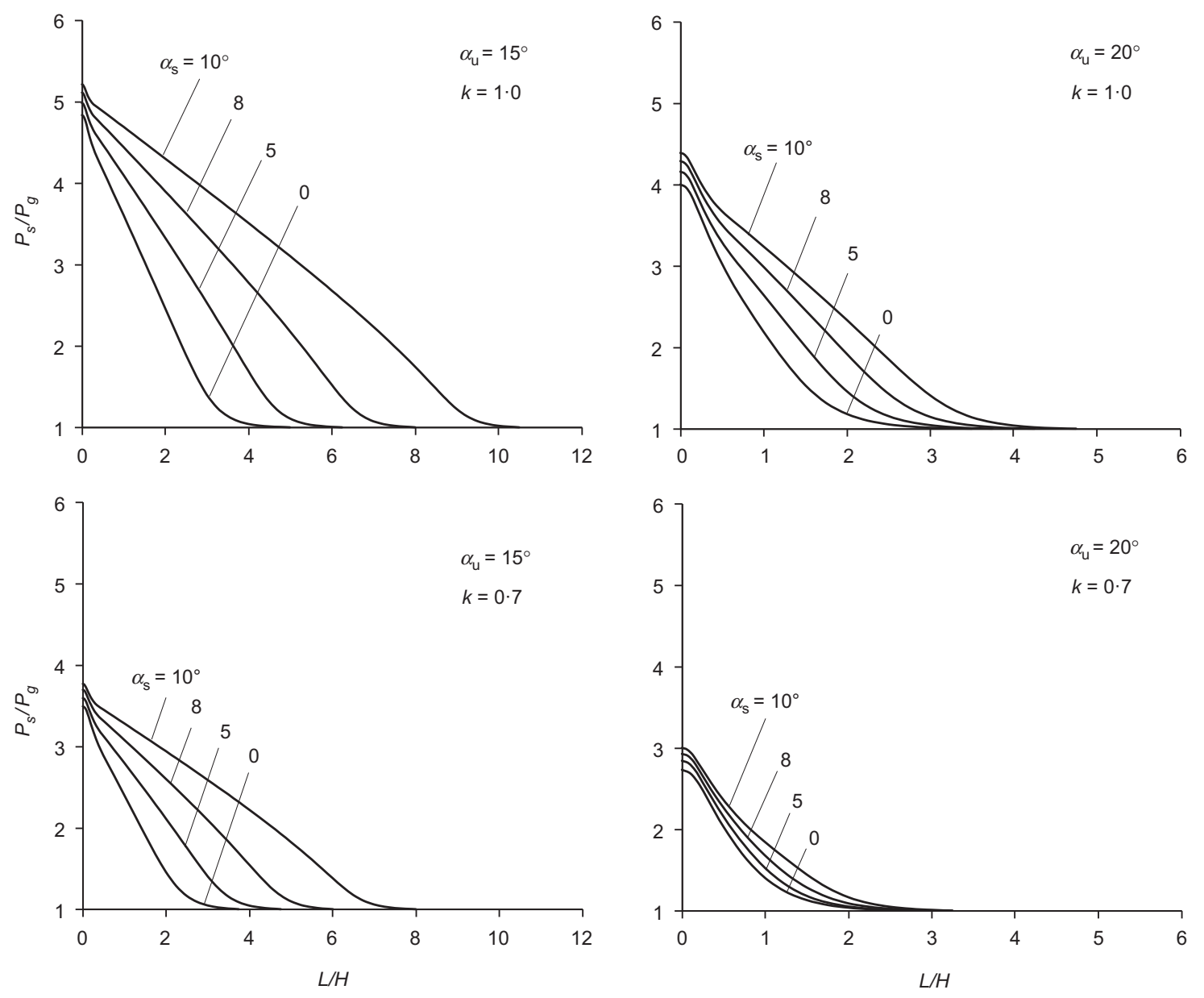

Fig. 8. The normalised total lateral force on the structure embedded at the normalised distance $L / H$ downslope from the landslide for a variety of slope inclinations and depths of phreatic surface ( $L$ is defined in Fig. 6). In the general case, total lateral forces are defined by equations (45)-(51); for smaller landslide pressures or closer distance to the landslide, by equations (70), (73) and (74) 
Similarly to the previous section, the lengths of the elastic zone $l_{\mathrm{ez}}$, process zone $l_{\mathrm{pz}}$ and fully softened zone $l_{\mathrm{sz}}$ are not known and will have to be determined by solving differential equations (26) together with the corresponding boundary conditions.

Earth pressures in the elastic zone are found by solving the first equation (26) with the boundary conditions (of peak shear strength at the upper boundary and zero net force in the far field)

$$
t=0: \frac{\mathrm{d} \Delta P}{\mathrm{~d} x}=\Delta \tau_{\mathrm{p}}=(1-r)\left(\tau_{\mathrm{p}}-\tau_{\mathrm{r}}\right) ; \quad t=-\infty: \Delta P=0
$$

The resulting solution is given by

$$
\Delta P=(1-r)\left(\tau_{\mathrm{p}}-\tau_{\mathrm{r}}\right) l_{\mathrm{e}} \mathrm{e}^{t / l_{\mathrm{e}}}
$$

where $l_{\mathrm{e}}$ is the characteristic elastic length from equation (30). The length of the elastic shearing zone is found from the condition that at $t=-l_{\mathrm{ez}}$ the net force drops to $\Delta P=\varepsilon P_{g}$

$$
l_{\mathrm{e} z}=l_{\mathrm{e}} \ln \frac{(1-r)\left(\tau_{\mathrm{p}}-\tau_{\mathrm{r}}\right) l_{\mathrm{e}}}{\varepsilon P_{g}}
$$

Next, the length of the process zone $l_{\mathrm{pz}}$ is determined. Equations (34)-(36) are solved with the boundary conditions at $t=0$

$$
\bar{\delta}^{\mathrm{p}}=0 ; \quad \frac{\mathrm{d} \bar{\delta}^{\mathrm{p}}}{\mathrm{d} \bar{t}}=\left.\frac{1}{\beta^{2}} \Delta \bar{P}\right|_{\bar{t}=0}=(1-r) \frac{\sqrt{1-\beta^{2}}}{\beta^{2}}
$$

where the second condition is obtained from equilibrium at the boundary with the elastic shearing zone $t=0$, where the net lateral force is defined from equation (54). Solutions are given by a degenerate case $b=1$ of equations (38)-(41), resulting in the length of the process zone

$$
l_{\mathrm{pz}}=l_{\mathrm{u}} \beta\left(\arcsin \beta+\arcsin \frac{\beta r}{1-r}\right)
$$

and the net lateral (slope parallel) force

$$
\Delta P=(1-r)\left(\tau_{\mathrm{p}}-\tau_{\mathrm{r}}\right) l_{\mathrm{u}} \cos \left(\arcsin \beta-\frac{t}{l_{\mathrm{u}} \beta}\right)
$$

Finally, the length of the fully softened zone, $l_{\mathrm{sz}}$, is calculated by solving the third equation (26) (resulting in the linear lateral force distribution), together with known earth pressures at both tips of the fully softened zone

$$
l_{\mathrm{s} z}=\frac{\Delta P_{\mathrm{ls}}-\Delta P_{\mathrm{pz}}}{\Delta \tau_{\mathrm{r}}}=\frac{\Delta P_{\mathrm{ls}}-\Delta P_{\mathrm{pz}}}{-r\left(\tau_{\mathrm{p}}-\tau_{\mathrm{r}}\right)}
$$

where the force at the top of the stable slope $\Delta P_{\mathrm{ls}}=E_{\mathrm{ls}}-P_{g}$ is the net landslide force determined from equations (18) and (21), while the net force $\Delta P_{\mathrm{pz}}$ is given for $t=l_{\mathrm{pz}}$ by equation (58):

$$
\Delta P_{\mathrm{pz}}=\left(\tau_{\mathrm{p}}-\tau_{\mathrm{r}}\right) l_{\mathrm{u}} \sqrt{(1-r)^{2}-\beta^{2} r^{2}}
$$

Dimensions and earth pressures of the landslide influence zone Substituting equations (55), (57) and (59) into equation (52) produces the normalised length of the landslide influence zone

$$
\begin{aligned}
\bar{L}_{\mathrm{iz}}= & \frac{L_{\mathrm{iz}}}{l_{\mathrm{u}}}=\sqrt{1-\beta^{2}} \ln \frac{(1-r) \sqrt{1-\beta^{2}}}{\varepsilon \bar{P}_{g}} \\
& +f(\beta, r, 1)+\frac{1}{-r}\left(\bar{E}_{\mathrm{ls}}-\bar{P}_{g}\right)
\end{aligned}
$$

where all the parameters are defined in equations (46)-(50).

Normalised lateral forces requiring support during excavation within the landslide influence zone can be expressed as a function of the normalised distance from the landslide boundary using equation (54) for the elastic shearing zone, equation (58) for the process zone and the linear lateral force distribution for the fully softened zone

$$
\begin{aligned}
& \frac{P}{P_{g}}=\frac{\bar{E}_{\mathrm{ls}}}{\bar{P}_{g}}+\left[1+\frac{\sqrt{(1-r)^{2}-\beta^{2} r^{2}}}{\bar{P}_{g}}-\frac{\left.\bar{E}_{\mathrm{ls}}\right]}{\bar{P}_{g}}\right] \frac{\bar{L}}{\bar{l}_{\mathrm{sZ}}} \text { for } 0<\bar{L} \leq \bar{l}_{\mathrm{sz}} \\
& \frac{P}{P_{g}}=1+\frac{(1-r)}{\bar{P}_{g}} \cos \left(\arcsin \beta-\frac{\bar{l}_{\mathrm{pz}}+\bar{l}_{\mathrm{sz}}-\bar{L}}{\beta}\right) \text { for } \bar{l}_{\mathrm{sz}}<\bar{L} \leq \bar{l}_{\mathrm{pz}}+\bar{l}_{\mathrm{sz}} \\
& \frac{P}{P_{g}}=1+\frac{(1-r) \sqrt{1-\beta^{2}}}{\bar{P}_{g}} \mathrm{e}^{-\left(\bar{L}-\bar{l}_{\mathrm{pz}}-\bar{l}_{\mathrm{sz}}\right) / \sqrt{1-\beta^{2}}} \text { for } \bar{l}_{\mathrm{pz}}+\bar{l}_{\mathrm{sz}}<\bar{L}
\end{aligned}
$$

where

$$
\begin{aligned}
& \bar{l}_{\mathrm{pz}}=\beta\left(\arcsin \beta+\arcsin \frac{\beta r}{1-r}\right) \\
& \bar{l}_{\mathrm{sz}}=\frac{\bar{E}_{\mathrm{ls}}-\bar{P}_{g}}{-r}-\sqrt{(1 / r-1)^{2}-\beta^{2}}
\end{aligned}
$$
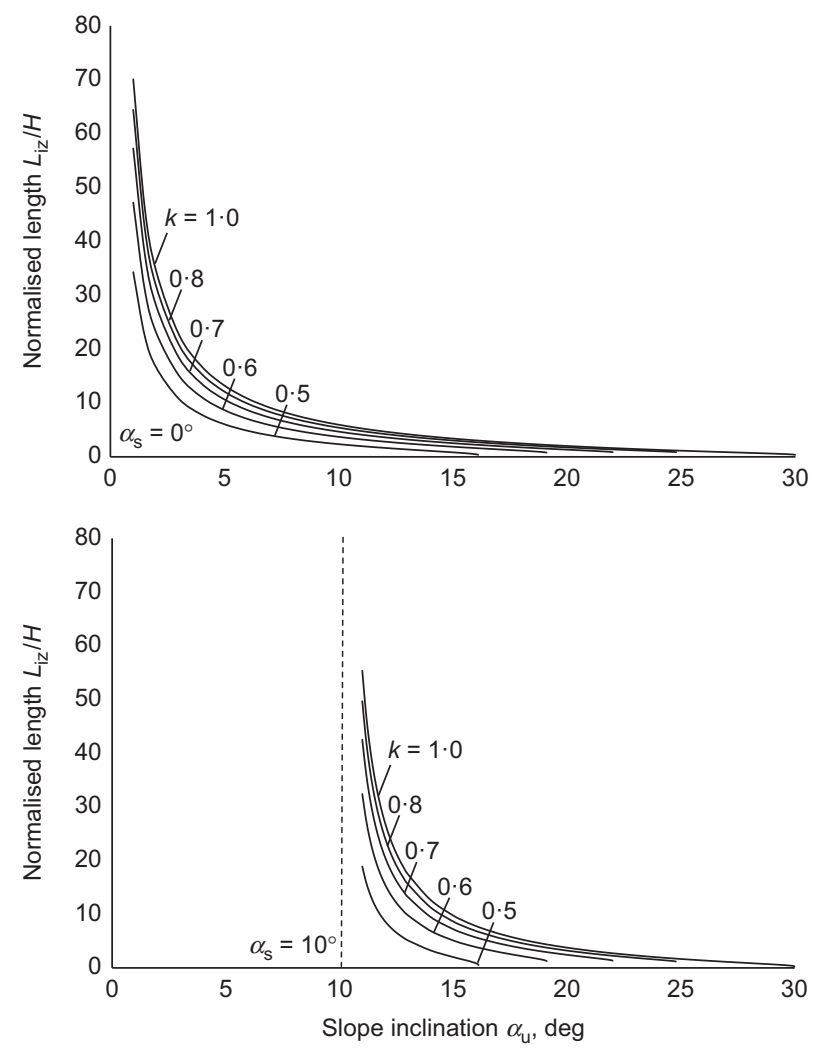

Fig. 9. Normalised length of the influence zone (for $\varepsilon=5 \%$ ) plotted against the slope inclination of the unstable part, for three inclinations of the stable portion of the slope and for a variety of phreatic surface locations embedded in parameter $k$. In the general case, the length is defined by equation (61), but for smaller landslide pressures, by equations (80) and (83) 
Lateral forces $\bar{E}_{\mathrm{ls}}$ and $\bar{P}_{g}$ are determined from equations (48)-(50).

For a special case of smaller landslide pressures, where the slip surface and process zones cannot fully develop, the length of the landslide influence zone and the earth pressures within it are calculated in Appendix 4. Note that the normalised solutions in equations (61)-(63) depend on elastic properties by way of parameter $\beta$.

\section{Parametric study}

The length of the landslide influence zone is defined by equation (61) in the general case, and by equations (80) and (83) in Appendix 4 for smaller landslide pressures. The following parametric study explores the effects of the slope inclination in the unstable $\alpha_{\mathrm{u}}$ and stable $\alpha_{\mathrm{s}}$ parts of the slope, as well as of the phreatic surface position $H_{\mathrm{w}} / H=$ $\gamma / \gamma_{\mathrm{w}}(1-k) \leq 1$ above the slip surface. Fig. 9 shows the normalised length of the influence zone $L_{\mathrm{iz}} / H$ (for $\varepsilon=5 \%$ ) as a function of the slope inclination of the unstable part $\alpha_{\mathrm{u}}$, for slope inclinations of the stable part $\alpha_{\mathrm{s}}=0$ and $10^{\circ}$ and groundwater levels $H_{\mathrm{w}} / H=0.0,0.4, \quad 0.6, \quad 0.8$ and 1.0 . To reduce here also the number of free parameters, $l_{\mathrm{u}} \approx H$, is assumed, with the remaining parameters given by $\phi^{\prime}=$ $30^{\circ} ; \gamma=20 \mathrm{kN} / \mathrm{m}^{3} ; \gamma_{\mathrm{w}}=10 \mathrm{kN} / \mathrm{m}^{3} ; \quad \beta=0.9 ; s=2 ; K_{0}=0.5$

The same parameters were adopted in equations $(62),(63)$, (84) and (85) to investigate the effects of $\alpha_{\mathrm{u}}, \alpha_{\mathrm{s}}$ and $H_{\mathrm{w}} / H$ on the earth pressures in the landslide influence zone in Figs 10 and 11, for deeper and shallower locations of phreatic surface, respectively. Here the normalised total lateral force $P / P_{g}$ is plotted against the normalised distance $L / H$ from the landslide (solid line), and compared to the pressures on the structure embedded at the same distance (dashed line).
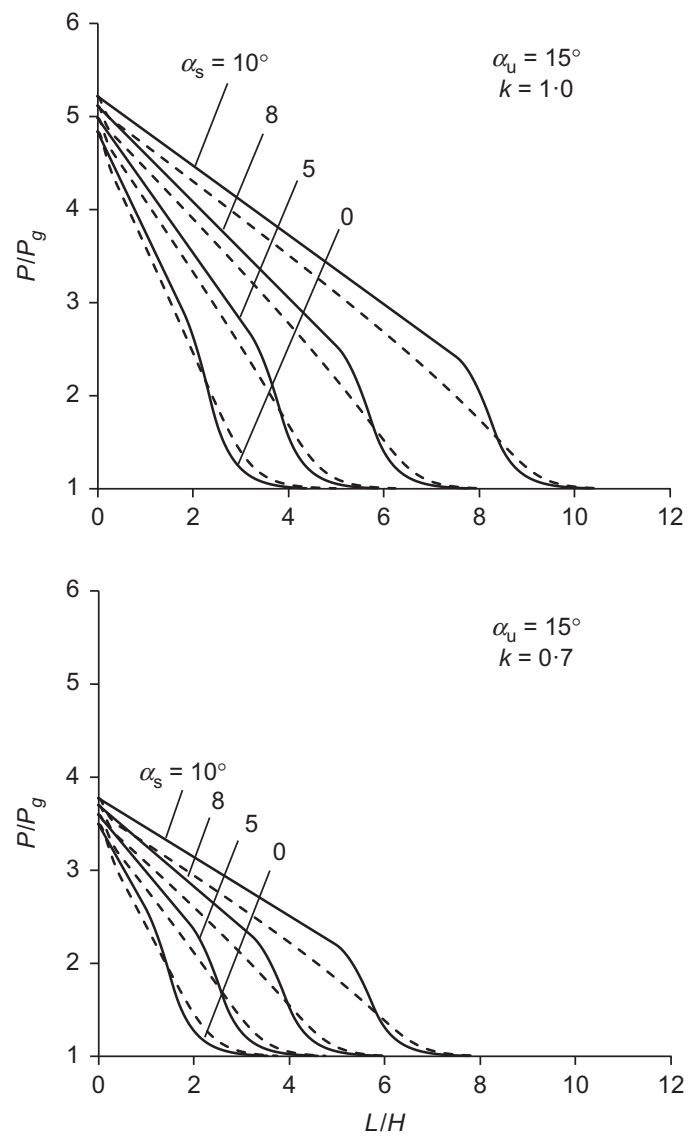

Fig. 10. The normalised total lateral force in the stable slope calculated using equations (62) and (63) for the general case, or from equations (84) and (85) for smaller landslide pressures, and plotted (solid line) against the normalised distance $L / H$ from the landslide for deeper phreatic surfaces $(k \geq 0.7)$. Dashed lines indicate the pressure on the structure embedded at the same distance
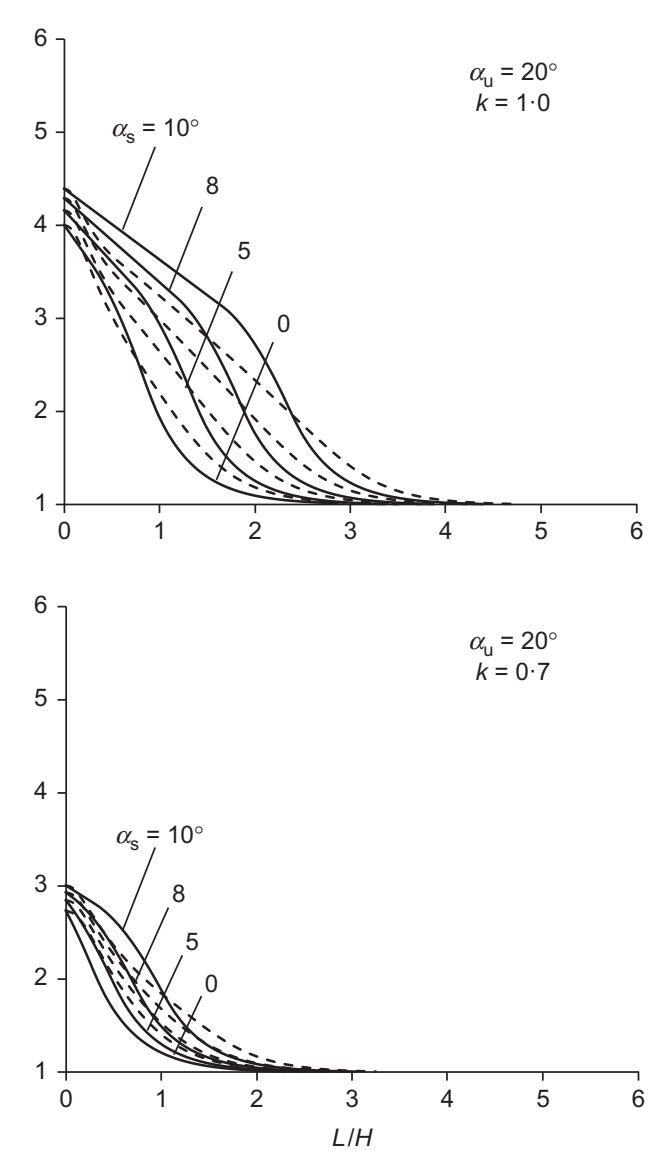

Note, that following condition (16), for a steeper unstable slope of $\alpha_{\mathrm{u}}=20^{\circ}$, higher locations of the phreatic surface $(k<0.7)$ are not possible.

From Fig. 9, it follows that a steeper inclination of the unstable part of the slope and a higher level of phreatic surface lead to a decrease in the length of the landslide influence zone. This seemingly counterintuitive conclusion can be explained by smaller landslide pressures and confirmed by Figs 10 and 11, where a steeper inclination of the unstable part of the slope and a higher level of phreatic surface lead to a decrease in the earth pressures in the landslide influence zone (similarly to the pressures acting on the structure). A steeper inclination of the stable part of the slope results in an increase in these pressures.

An interesting observation in Figs 10 and 11 is that often the pressures on the structure are lower than the pressures without structure. How is it possible that by constraining displacements, lower earth pressures are achieved? This can be explained by the effect of the slip surface growth: lower displacements lead to less softening on the slip surface and in the process zone, resulting in the higher shear strength on the slip surface, and, therefore, requiring smaller pressures to keep the sliding layer in equilibrium. When the slip surface and process zone do not develop, the behaviour is elastic and the presence of the structure leads to an increase in stresses (also observed in Figs 10 and 11) due to constrained displacements.

\section{A CASE STUDY}

In 1979 a local landslide of $24000 \mathrm{~m}^{3}$ was triggered by an excavation in Zurich, just above the bottom of the larger historic landslide of 1770 mapped in Fig. 1(b). The $7 \mathrm{~m}$ thick 

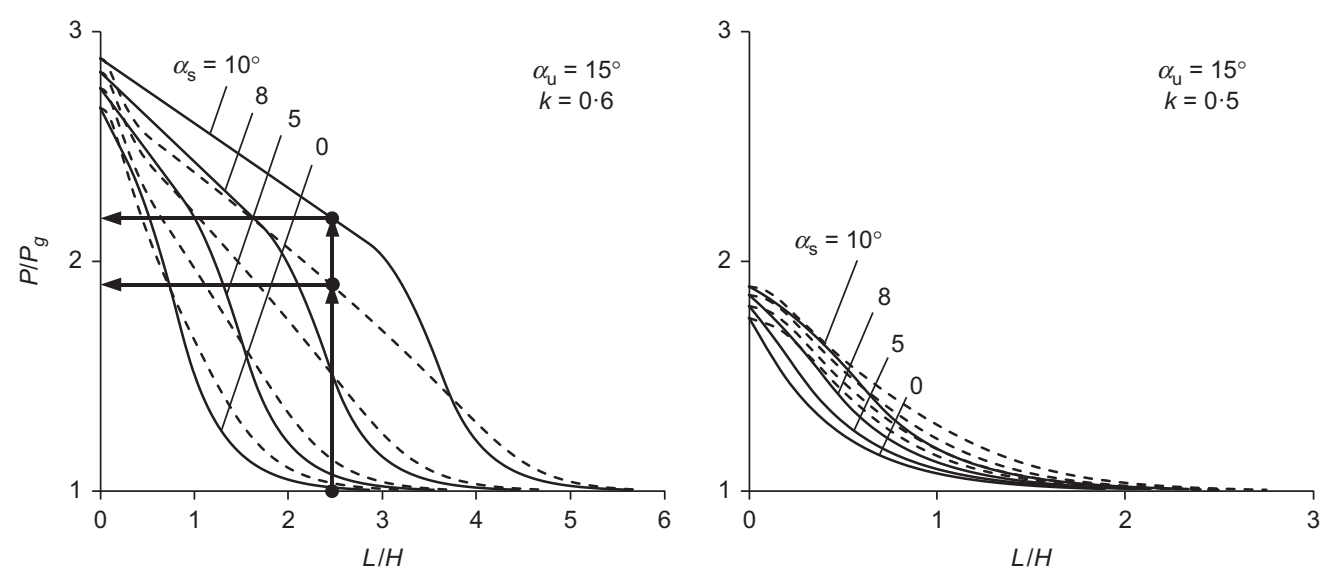

Fig. 11. The normalised total lateral force in the stable slope calculated using equations (62) and (63) for the general case, or from equations (84) and (85) for smaller landslide pressures, and plotted (solid line) against the normalised distance $\boldsymbol{L} \boldsymbol{H}$ from the landslide for phreatic surfaces that are closer to the ground surface $(k<0.7)$. Dashed lines indicate the pressure on the structure embedded at the same distance. Arrows indicate values relevant to the case study

sliding body moved about $10 \mathrm{~cm}$, causing damage to the houses, retaining walls and roads at its perimeter. The lower boundary of this recent slide, which has also been the lower boundary of the historic 1770 slide, coincides with the location where the inclination of the underlying bedrock changes from 15 to $10^{\circ}$. This location has been determined from multiple boreholes both upslope and downslope from the boundary, some of them instrumented by inclinometer pipes. Houses below the slide were not damaged in 1979, but recently one of them, located $17 \mathrm{~m}$ below the landslide boundary, had to be replaced by a new structure. The main question for the designers was to determine the total force currently acting on the structure, in order to calculate the anchor forces necessary to support the excavation and prevent reactivation of the landslide.

Because the parametric studies in Figs 8-11 were centred around the parameters of this particular case study: $l_{\mathrm{u}} \approx H$; $\phi^{\prime}=30^{\circ} ; \gamma=20 \mathrm{kN} / \mathrm{m}^{3} ; \gamma_{\mathrm{w}}=10 \mathrm{kN} / \mathrm{m}^{3} ; \beta=0.9 ; s=2 ; K_{0}=$ 0.5 , the corresponding plots can be used to determine the length of the influence zone and the pressure on the structure. For inclinations of the unstable and stable parts $\alpha_{\mathrm{u}}=15^{\circ}$ and $\alpha_{\mathrm{s}}=10^{\circ}$ and the highest observed groundwater level $H_{\mathrm{w}} / H=$ $0 \cdot 8(k=0 \cdot 6)$, from Fig. 9 and the left plot in Fig. 11 the following can be determined

(a) $L_{\mathrm{iz}} / H \approx 5 \cdot 6$, so that for $H=7 \mathrm{~m}: L_{\mathrm{iz}} \approx 40 \mathrm{~m}-$ that is, larger than the distance to the structure $L=17 \mathrm{~m}$, which implies that the pressure acting on the structure is elevated

(b) for $L / H=17 \mathrm{~m} / 7 \mathrm{~m}=2.43$, the normalised earth pressure on the structure $P_{\mathrm{s}} / P_{g}=1.91$

(c) in the absence of the structure, if the excavation was performed on a bare slope $17 \mathrm{~m}$ below the landslide boundary, a higher pressure of $P / P_{g}=2.20$ would have to be supported.

The far-field total lateral earth pressure coefficient is determined from equation (21) as $K_{g}=0.63$. It follows that the actual total earth pressure coefficient on the existing structure is $K_{\mathrm{s}}=\left(P_{\mathrm{s}} / P_{g}\right) K_{g}=1 \cdot 20$, which appears to be close to the ultimate shear resistance of the existing building. It is critical that the excavation is supported for at least $K_{\mathrm{s}}=$ $1 \cdot 20$, because smaller anchor forces would cause downslope displacements of the sliding layer, leading to additional softening in the weak layer, that would necessitate additional support in excess of $K_{\mathrm{s}}=1 \cdot 20$.

\section{CONCLUSIONS}

The paper proposes a mechanism of downhill pressure transfer within the stable part of the slope below a landslide. The mechanism combines the failure at the bottom of the unstable part of the slope with progressive growth of the slip surface into the stable part. It allows determination of the dimensions of the 'landslide influence zone' below the landslide and the lateral earth pressures within it, providing some insights for design considerations.

This basic physical mechanism explains

(a) why a milder inclination of the unstable part of the slope and a lower level of phreatic surface lead to an increase both in the length of the landslide influence zone and in earth pressures acting in this zone (due to a larger landslide pressure)

(b) why a steeper inclination of the stable part of the slope also leads to an increase in earth pressures (due to a larger gravitational component)

(c) why the pressures on the structures embedded in the landslide influence zone are often lower than the pressures without structure (lower displacements lead to less softening on the slip surface).

Note that although this study has focused on a case where the depth of the weak layer is the same in the stable and unstable portions of the slope, it can easily be extended to a frequently observed case of two different depths. Indeed, both portions of the slope have been treated separately and coupled only by way of the landslide force, $E_{\mathrm{ls}}$, which can be easily adjusted to account for a different depth of the weak layer in the upper portion using equations (17) and (18).

In practical terms, insufficient support of the elevated earth pressures in the landslide influence zone can cause excessive displacements and even reactivation of the landslide. While many existing hazard maps do extend below the landslide toe, the proposed approach can help to quantify the dimensions of such zones and the pressures within them, and facilitate formulation of special regulations for construction activity.

\section{ACKNOWLEDGEMENTS}

The author would like to thank Dr Josef Grob and Dr Balz Friedli for the motivation and support they provided at different stages of this work, and Michelle Stucker for reviewing the manuscript. 


\section{APPENDIX 1. CLOSED-FORM APPROXIMATION OF EFFECTIVE EARTH PRESSURES}

The above approximation was obtained by linearising depth dependency of the total horizontal stress $\sigma_{x}^{\mathrm{W}}(z)$ in equation (5), which can now also be expressed by way of $K_{\mathrm{lh}}^{\mathrm{w}}(k)$ and $K_{\mathrm{lh}}^{\mathrm{d}}$

$$
\sigma_{x}^{\mathrm{w}}(z)=\gamma K_{\mathrm{lh}}^{\mathrm{d}} z-\gamma_{\mathrm{w}}\left[z-\left(H-H_{\mathrm{w}}\right)\right] \frac{K_{\mathrm{lh}}^{\mathrm{d}}-K_{\mathrm{lh}}^{\mathrm{w}}(k)}{1-k}
$$

providing the reasonably accurate linear distribution of the total horizontal stresses over the entire thickness of the sliding layer (both wet and dry)

$$
\sigma_{x}(z)=\gamma K_{\mathrm{lh}}^{\mathrm{d}} z-\gamma_{\mathrm{w}}\left\langle z-\left(H-H_{\mathrm{w}}\right)\right\rangle \frac{K_{\mathrm{lh}}^{\mathrm{d}}-K_{\mathrm{lh}}^{\mathrm{w}}(k)}{1-k}
$$

where

$$
\langle x\rangle=\left\{\begin{array}{l}
0, \text { for } x<0 \\
x, \text { for } x \geq 0
\end{array}\right.
$$

are the Macauley brackets.

Distribution of the effective horizontal stresses over the thickness of the sliding layer is then

$$
\sigma_{x}^{\prime}(z)=\sigma_{x}(z)-u=\gamma K_{\mathrm{lh}}^{\mathrm{d}} z-\gamma_{\mathrm{w}} z-\left(H-H_{\mathrm{W}}\right)\left[\frac{K_{\mathrm{lh}}^{\mathrm{d}}-K_{\mathrm{lh}}^{\mathrm{w}}(k)}{1-k}+\cos ^{2} \alpha\right]
$$

where $H_{\mathrm{w}} / H=\gamma / \gamma_{\mathrm{w}}(1-k)$ from equation (2), and the normalised approximate horizontal component of effective landslide force acting on a vertical plane is determined by

$$
\frac{E_{\mathrm{lh}}^{\prime}}{E_{\mathrm{lh}}^{\mathrm{d}}}=1-\frac{\gamma}{\gamma_{\mathrm{w}}}(1-k)\left[1-\frac{K_{\mathrm{lh}}^{\mathrm{w}}(k)-(1-k) \cos ^{2} \alpha}{K_{\mathrm{lh}}^{\mathrm{d}}}\right] ; E_{\mathrm{lh}}^{\mathrm{d}}=\frac{1}{2} K_{\mathrm{lh}}^{\mathrm{d}} \gamma H^{2}
$$

\section{APPENDIX 2. SMALLER LANDSLIDE PRESSURES}

The landslide pressure may not be sufficiently high to be able to drive the slip surface and form the process zone and a fully softened zone within the weak layer into the stable slope. Indeed, from equation (29) it follows that when the process zone is formed, the shear stress at its boundary $(t=0)$ with the elastic zone will reach the peak strength $\tau_{\mathrm{p}}$, so that the normalised net lateral force becomes

$$
\left.\Delta \bar{P}\right|_{\tau=\tau_{\mathrm{p}}}=(1-r) \sqrt{1-\beta^{2}} \operatorname{coth} \frac{l_{\mathrm{e} z}}{l_{\mathrm{e}}}
$$

If, however, the landslide force at the top of the stable slope $\Delta \bar{P}_{1 \mathrm{~s}}=$ $\bar{E}_{1 \mathrm{~s}}-\bar{P}_{g}$ is smaller than this net force $\left.\Delta \bar{P}\right|_{\tau=\tau_{\mathrm{p}}}$, the fully softened and process zones will not develop - that is, $L^{\tau=}=l_{\text {ez }}$. Solving the first equation (26) with the boundary conditions of the landslide force $\Delta P=E_{\mathrm{ls}}-P_{g}$ at the landslide boundary $t=0$ and zero displacement at the structure $t=-L$ gives the net force in the elastic zone

$$
\Delta P=\left(E_{\mathrm{ls}}-P_{g}\right) \frac{\cosh \left[(t+L) / l_{\mathrm{e}}\right]}{\cosh \left(L / l_{\mathrm{e}}\right)}
$$

and the lateral force on the embedded structure

$$
\frac{P_{\mathrm{s}}}{P_{g}}=1+\left(\frac{\bar{E}_{\mathrm{ls}}}{\bar{P}_{g}}-1\right) \frac{1}{\cosh \left(\bar{L} / \sqrt{1-\beta^{2}}\right)}, \text { for } \bar{E}_{\mathrm{ls}}-\bar{P}_{\mathrm{g}} \leq\left.\Delta \bar{P}\right|_{\tau=\tau_{\mathrm{p}}}
$$

The process zone will start developing when the net landslide force $\bar{E}_{1 \mathrm{~s}}-\bar{P}_{g}>\left.\Delta \bar{P}\right|_{\tau=\tau_{\mathrm{n}}}$. For the slip surface (i.e. fully softened zone) to start growing, the shear stress at the end of the process zone $t=l_{\mathrm{pz}}$ has to drop to the residual strength $\tau_{\mathrm{r}}$, in which case the normalised net lateral force at $t=l_{\mathrm{pz}}$ is given by equation (43)

$$
\left.\Delta \bar{P}\right|_{\tau=\tau_{\mathrm{r}}}=\sqrt{b^{2}(1-r)^{2}-\beta^{2} r^{2}}
$$

If, however, the landslide force at the top of the stable slope $\Delta \bar{P}_{\mathrm{ls}}=$ $\bar{E}_{\mathrm{ls}}-\bar{P}_{g}$ is smaller than this net force $\left.\Delta \bar{P}\right|_{\tau=\tau_{\mathrm{r}}}$, the process zones will develop only partially, while the fully softened zone will not develop at all. The length of the partially developed process zone can be found from equation (40) and the condition $\Delta \bar{P}=\bar{E}_{\mathrm{ls}}-\bar{P}_{g}$ at $t=l_{\mathrm{pz}}$

$$
\bar{l}_{\mathrm{pz}}=\frac{l_{\mathrm{pz}}}{l_{\mathrm{u}}}=\beta\left[\arcsin \frac{\beta}{b}-\arccos \frac{\bar{E}_{\mathrm{ls}}-\bar{P}_{g}}{b(1-r)}\right]
$$

Resolving equations

$$
\begin{gathered}
\bar{L}=\bar{l}_{\mathrm{ez}}+\bar{l}_{\mathrm{pz}}=\hat{l}_{\mathrm{ez}} \sqrt{1-\beta^{2}}+\beta\left[\arcsin \frac{\beta}{b}-\arccos \frac{\bar{E}_{\mathrm{ls}}-\bar{P}_{g}}{b(1-r)}\right] \\
b=\sqrt{\beta^{2}+\left(1-\beta^{2}\right) \operatorname{coth}^{2} \hat{l}_{\mathrm{ez}}}
\end{gathered}
$$

with respect to $\hat{l}_{\mathrm{ez}}(\bar{L})$ and substituting it into equation (51) provides the lateral force acting on the structure

$$
\frac{P_{\mathrm{S}}}{P_{g}}=1+\frac{(1-r) \sqrt{1-\beta^{2}}}{\bar{P}_{g} \sinh \left[\hat{l}_{\mathrm{ez}}(\bar{L})\right]}, \text { for }\left.\Delta \bar{P}\right|_{\tau=\tau_{\mathrm{p}}}<\bar{E}_{\mathrm{ls}}-\bar{P}_{g} \leq\left.\Delta \bar{P}\right|_{\tau=\tau_{\mathrm{r}}}
$$

It follows that the slip surface will grow in the weak layer only when $\left.\Delta \bar{P}\right|_{\tau=\tau_{\mathrm{r}}}<\bar{E}_{\mathrm{ls}}-\bar{P}_{g}$, with the lateral forces acting on the structure calculated using equations (45)-(51).

\section{APPENDIX 3. STRUCTURES CLOSE TO THE LANDSLIDE BOUNDARY}

When an embedded structure is located close to the landslide boundary, the displacements caused by compression of the sliding layer may not be sufficient to generate enough shear deformation within the weak layer in order to form the fully softened and the process zones. This can happen even for higher landslide pressures, which would normally cause formation of the process zone if the structure was sufficiently remote. Indeed, when the landslide force at the top of the stable slope $\Delta \bar{P}_{1 \mathrm{~s}}=\bar{E}_{\mathrm{ls}}-\bar{P}_{g}$ is larger than the net force $\left.\Delta \bar{P}\right|_{\tau=\tau_{\mathrm{r}}}$ in equation (68), but the distance to the embedded structure is shorter than the limit $\bar{L}_{\mathrm{e}}$

$$
\bar{L}=\frac{L}{l_{\mathrm{u}}}=\frac{l_{\mathrm{ez}}}{l_{\mathrm{u}}} \leq \bar{L}_{\mathrm{e}}=\sqrt{1-\beta^{2}} \operatorname{atanh} \frac{(1-r) \sqrt{1-\beta^{2}}}{\bar{E}_{\mathrm{ls}}-\bar{P}_{g}}
$$

derived using condition (68) with $\left.\Delta \bar{P}\right|_{\tau=\tau_{\mathrm{p}}}=\bar{E}_{\mathrm{ls}}-\bar{P}_{g}$, the fully softened and process zones will not develop, and the pressure on the embedded structure will be given by equation (70).

When $\bar{L}>\bar{L}_{\mathrm{e}}$, the process zone will partially develop, but it will be shorter than its fully developed length given by equation (41), even for high landslide forces of $\left.\Delta \bar{P}\right|_{\tau=\tau_{\mathrm{r}}}<\bar{E}_{\mathrm{ls}}-\bar{P}_{g}$ that would normally cause formation of the fully softened zone (i.e. the growth of the slip surface) if the structure was sufficiently remote. To initiate the growth of the slip surface, the distance to the embedded structure should exceed the critical length derived from equations (39) and (41)

$$
\begin{aligned}
\bar{L} & =\frac{L}{l_{\mathrm{u}}}>\bar{L}_{\mathrm{cr}}=\bar{l}_{\mathrm{ez}}+\bar{l}_{\mathrm{pz}} \\
& =\sqrt{1-\beta^{2}} \operatorname{atanh} \sqrt{\frac{1-\beta^{2}}{b^{2}-\beta^{2}}}+\beta\left[\arcsin \frac{\beta}{b}+\arcsin \frac{\beta r}{b(1-r)}\right]
\end{aligned}
$$

where $b$ is derived using condition (71) with the shear strength at $t=l_{\mathrm{pz}}$ assumed to drop to its residual value $\tau_{\mathrm{r}}$ for $\left.\Delta \bar{P}\right|_{\tau=\tau_{\mathrm{r}}}=\bar{E}_{\mathrm{ls}}-\bar{P}_{g}$

$$
b=\frac{\sqrt{\left(\bar{E}_{\mathrm{ls}}-\bar{P}_{g}\right)^{2}+\beta^{2} r^{2}}}{1-r}
$$

It follows that for $\bar{L}_{\mathrm{e}}<\bar{L} \leq \bar{L}_{\text {cr }}$, the lateral force acting on the structure can be calculated using equations (73) and (74). For the general case of $\bar{L}>\bar{L}_{\text {cr }}$, with all the three zones fully developed, the lateral forces acting on the structure are calculated using equations (45)-(51). 


\section{APPENDIX 4. LANDSLIDE INFLUENCE ZONE FOR SMALLER LANDSLIDE PRESSURES}

Similarly to the case of an embedded structure, the landslide pressure may not be sufficiently high to be able to drive the slip surface into the stable slope. From equation (54) it follows that for the process zone to start forming, the shear stress at its boundary $t=0$ with the elastic zone should reach the peak strength $\tau_{\mathrm{p}}$, with the normalised net lateral force

$$
\left.\Delta \bar{P}\right|_{\tau=\tau_{\mathrm{p}}}=(1-r) \sqrt{1-\beta^{2}}
$$

If the landslide force at the top of the stable slope $\Delta \bar{P}_{1 \mathrm{~s}}=\bar{E}_{\mathrm{ls}}-\bar{P}_{g}$ is smaller than this net force $\left.\Delta \bar{P}\right|_{\tau=\tau}$, the process zones will not develop and the behaviour in the weak layer is purely elastic - that is $L=l_{\mathrm{e} z}$. Solving the first equation (26) with the boundary conditions $\Delta P=E_{\mathrm{ls}}-P_{g}$ at the landslide boundary $t=0$ and zero net lateral force in the far field gives

$$
\Delta P=\left(E_{\mathrm{ls}}-P_{g}\right) \mathrm{e}^{t / l_{\mathrm{e}}}
$$

which gives the normalised length of the landslide influence zone

$$
\bar{L}_{\mathrm{iz}}=\frac{L_{\mathrm{iz}}}{l_{\mathrm{u}}}=\sqrt{1-\beta^{2}} \ln \frac{\bar{E}_{\mathrm{ls}}-\bar{P}_{g}}{\varepsilon \bar{P}_{g}}, \text { for } \bar{E}_{\mathrm{ls}}-\bar{P}_{g} \leq(1-r) \sqrt{1-\beta^{2}}
$$

The process zone will start developing when the net landslide force $\bar{E}_{1 \mathrm{~s}}-\bar{P}_{g}>\left.\Delta \bar{P}\right|_{\tau=\tau}$. For the slip surface (i.e. fully softened zone) to start growing, the shear stress at the end of the process zone $t=l_{\mathrm{pz}}$ has to drop to the residual strength $\tau_{\mathrm{r}}$, in which case the normalised net lateral force at $t=l_{\mathrm{pz}}$ is given by equation (60)

$$
\left.\Delta \bar{P}\right|_{\tau=\tau_{\mathrm{r}}}=\Delta \bar{P}_{\mathrm{pz}}=\sqrt{(1-r)^{2}-\beta^{2} r^{2}}
$$

If the pressure at the top of the stable slope $\Delta \bar{P}_{\mathrm{ls}}=\bar{E}_{\mathrm{ls}}-\bar{P}_{g}$ is smaller than this net force $\left.\Delta \bar{P}\right|_{\tau=\tau_{\tau}}$, the process zones will develop only partially, while the fully softened zone will not develop at all that is, $L=l_{\mathrm{ez}}+l_{\mathrm{pz}}$. The length of the elastic zone $l_{\mathrm{ez}}$ is given by equation (55), while the partially developed process zone can be found from equation (58) and the condition $\Delta \bar{P}=\bar{E}_{\mathrm{ls}}-\bar{P}_{\mathrm{g}}$ at $t=l_{\mathrm{pz}}$

$$
\bar{l}_{\mathrm{pz}}=\frac{l_{\mathrm{pz}}}{l_{\mathrm{u}}}=\beta\left[\arcsin \beta-\arccos \frac{\bar{E}_{\mathrm{ls}}-\bar{P}_{g}}{(1-r)}\right]
$$

The normalised length of the landslide influence zone $\bar{L}=\bar{l}_{\text {ez }}+$ $\bar{l}_{\mathrm{pz}}$ is in this case

$$
\begin{gathered}
\bar{L}=\sqrt{1-\beta^{2}} \ln \frac{(1-r) \sqrt{1-\beta^{2}}}{\varepsilon \bar{P}_{g}}+\beta\left[\arcsin \beta-\arccos \frac{\bar{E}_{\mathrm{ls}}-\bar{P}_{g}}{(1-r)}\right] \\
\quad \text { for }(1-r) \sqrt{1-\beta^{2}} \leq \bar{E}_{\mathrm{ls}}-\bar{P}_{g} \leq \sqrt{(1-r)^{2}-\beta^{2} r^{2}}
\end{gathered}
$$

When the landslide pressure is not sufficiently high for the process zone or the fully softened zone to start developing, the lateral forces in the landslide influence zone are found using equation (79) for $\bar{E}_{\mathrm{ls}}-\bar{P}_{g} \leq(1-r) \sqrt{1-\beta^{2}}$ :

$$
\frac{P}{P_{g}}=1+\left(\frac{\bar{E}_{\mathrm{ls}}}{\bar{P}_{g}}-1\right) \mathrm{e}^{-\bar{L} / \sqrt{1-\beta^{2}}}
$$

and equation (58) for $(1-r) \sqrt{1-\beta^{2}} \leq \bar{E}_{\mathrm{ls}}-\bar{P}_{g} \leq \sqrt{(1-r)^{2}-\beta^{2} r^{2}}$ :

$$
\begin{gathered}
\frac{P}{P_{g}}=1+\frac{(1-r)}{\bar{P}_{g}} \cos \left(\arcsin \beta-\frac{\bar{l}_{\mathrm{pz}}-\bar{L}}{\beta}\right), \text { for } 0 \leq \bar{L} \leq \bar{l}_{\mathrm{pz}} \\
\frac{P}{P_{g}}=1+\frac{(1-r) \sqrt{1-\beta^{2}}}{\bar{P}_{g}} \mathrm{e}^{-\left(\bar{L}-\bar{l}_{\mathrm{pz}}\right) / \sqrt{1-\beta^{2}}}, \text { for } \bar{l}_{\mathrm{pz}}<\bar{L}
\end{gathered}
$$

where $\bar{l}_{\mathrm{pz}}$ is adopted from equation (82).

\section{NOTATION}

$d$ thickness of the weak layer

$E^{\prime}$ plane-strain elastic modulus of the sliding layer

$E_{\mathrm{lh}}$ horizontal component of the total landslide pressure

$E_{\mathrm{lh}}^{\mathrm{d}}$ horizontal landslide pressure for the entirely dry sliding layer

$E_{\mathrm{ls}}$ slope-parallel component of the total landslide pressure

$G$ elastic shear modulus of the weak layer

$G^{\mathrm{p}}$ softening modulus of the weak layer

$H$ depth of the weak layer

$H_{\mathrm{w}}$ depth of the phreatic surface above the weak layer

$h$ thickness of the sliding layer

$K_{0} \quad$ effective at rest earth pressure coefficient

$K_{g} \quad$ total far-field lateral earth pressure coefficient

$K_{\mathrm{lh}}^{\mathrm{d}} \quad$ horizontal earth pressure coefficient above the phreatic surface

$K_{\mathrm{lh}}^{\mathrm{w}}$ horizontal total earth pressure coefficient below the phreatic surface

$k$ ratio between the slope and residual friction angles of the weak layer

$L$ distance between the structure and the landslide boundary

$L_{\mathrm{iz}} \quad$ length of the landslide influence zone

$l_{\mathrm{e}} \quad$ characteristic elastic length

$l_{\mathrm{ez}} \quad$ length of the elastic shearing zone

$l_{\mathrm{pz}}$ length of the process zone

$l_{\mathrm{sz}}$ length of the fully softened zone (the slip surface)

$l_{\mathrm{u}} \quad$ characteristic length

$n$ the coordinate normal to the slope

$P$ lateral force in the stable part of the slope

$P_{g} \quad$ far-field lateral force in the stable part of the slope

$P_{\mathrm{pz}} \quad$ lateral force at the boundary between the slip surface and the process zone

$P_{\mathrm{s}} \quad$ lateral force acting on the structure embedded in the stable part of the slope

$r$ shear stress ratio

$s \quad$ sensitivity $\left(=\tau_{\mathrm{p}} / \tau_{\mathrm{r}}\right)$

$t$ slope-parallel coordinate

$u$ groundwater pressure

$v$ slope-parallel displacements of the sliding layer

$\alpha$ slope inclination

$\alpha_{\mathrm{s}}$ inclination of the stable part of the slope

$\alpha_{\mathrm{u}}$ inclination of the unstable part of the slope

$\beta$ stiffness parameter of the weak layer

$\gamma$ total unit weight of soil

$\gamma^{\mathrm{p}} \quad$ plastic shear strain in the weak layer

$\gamma_{\mathrm{r}}^{\mathrm{p}} \quad$ plastic shear strain required to fully soften the material

$\gamma_{\mathrm{w}}$ unit weight of the water

$\delta^{\mathrm{p}} \quad$ plastic shear displacement over the weak layer

$\delta_{\mathrm{r}}^{\mathrm{p}} \quad$ plastic shear displacement required to fully soften the material

$\varepsilon \quad$ percentage of excess net earth pressure defining the $L_{\mathrm{iz}}$ boundary

$\sigma_{\mathrm{n}}^{\prime} \quad$ effective normal stress acting on the weak layer

$\tau$ shear stress acting in the weak layer

$\tau_{g} \quad$ gravitational shear stress

$\tau_{\mathrm{p}} \quad$ peak shear strength

$\tau_{\mathrm{r}} \quad$ residual shear strength

$\phi^{\prime} \quad$ effective angle of internal friction of the sliding layer

$\phi_{\mathrm{p}}^{\prime} \quad$ peak effective angle of internal friction of the sliding layer

$\phi_{\mathrm{r}}^{\prime}$ residual effective angle of internal friction of the sliding layer

\section{REFERENCES}

Bernander, S. \& Olofsson, J. (1981). On formation of progressive failures in slopes. In Proceedings of the 10th international conference on soil mechanics and foundation engineering, Stockholm, Sweden, vol. 3, pp. 357-362. Rotterdam, the Netherlands: Balkema.

Bernander, S., Gustas, H. \& Olofsson, J. (1989). Improved model for progressive failure analysis of slope stability. In Proceedings of the 12th international conference on soil mechanics and foundation engineering, Rio de Janeiro, Brazil, vol. 3, pp. 1539-1542. Rotterdam, the Netherlands: Balkema.

Brandl, H. \& Dalmatiner, J. (1988). Brunnenfundierungen von Bauwerken in Hängen (insbesondere Brücken), Heft 352. Vienna, Austria: Schriftenreihe Strassenforschung des Bundesministeriums für wirtschaftliche Angelegenheiten (in German). 
Chu, S. C. (1991). Rankine's analysis of active and passive pressures in dry sands. Soils Found. 31, No. 4, 115-120. https://doi.org/ 10.3208/sandf1972.31.4_115.

Dey, R., Hawlader, B., Phillips, R. \& Soga, K. (2012). Effects of shear band propagation on submarine landslide. In Proceedings of the 22nd international offshore and polar engineering conference (ISOPE) (eds J. S. Chung and W. C. Kan), vol. 2, pp. 766-772. Cupertino, CA, USA: ISOPE.

Friedli, B. (2018). Earth pressures in landslides and applications of fibre-optic sensors in geomechanic. PhD thesis, ETH Zürich, Zurich, Switzerland.

Friedli, B., Hauswirth, D. \& Puzrin, A. M. (2017). Lateral earth pressures in constrained landslides. Géotechnique 67, No. 10, 890-905. https://doi.org/10.1680/jgeot.16.P.158.

Haefeli, R. (1944). Zur erd- und kriechdruck-theorie. Schweizerische Bauzeitung 124, No. 20, pp. 256-260 (in German).

Hansbo, P., Larsson, R., Runesson, K. \& Wiberg, N. E. (1985). On the behaviour of natural slopes with emphasis on progressive failure. In Proceedings of the 11th international conference on soil mechanics and foundation engineering, San Francisco, vol. 2, pp. 757-761. Rotterdam, the Netherlands: Balkema.

Lateltin, O., Haemmig, C., Raetzo, H. \& Bonnard, C. (2005). Landslide risk management in Switzerland. Landslides 2, No. 4, 313-320, https://doi.org/10.1007/s10346-005-0018-8.

Locat, A., Jostad, H. P. \& Leroueil, S. (2013). Numerical modelling of progressive failure and its implications for spreads in sensitive clays. Can. Geotech. J. 50, No. 9, 961-978.

Mansour, M. F., Morgenstern, N. R. \& Martin, C. D. (2011). Expected damage from displacement of slow-moving slides. Landslides 8, No. 1, 117-131, https://doi.org/10.1007/s10346010-0227-7.

Muraro, S., Madaschi, A. \& Gajo, A. (2015). Passive soil pressure on sloping ground and design of retaining structures for slope stabilisation. Géotechnique 65, No. 6, 507-516. https://doi.org/ 10.1680/geot.14.P.211.

Palmer, A. C. \& Rice, J. R. (1973). The growth of slip surfaces in the progressive failure of overconsolidated clay. Proc. R. Soc. Lond., A 332, No. 1591, 527-548. https://doi.org/10.1098/rspa.1973. 0040 .

Palmisano, F., Vitone, C. \& Cotecchia, F. (2016). Methodology for landslide damage assessment. Procedia Engng 161, 511-515, https://doi.org/10.1016/j.proeng.2016.08.679.
Picarelli, L. (2011). Discussion to the paper 'Expected damage from displacement of slow-moving slides' by M. F. Mansour, N. R. Morgenstern and C. D. Martin. Landslides 8, No. 4, 553-555, https://doi.org/10.1007/s10346-011-0292-6.

Puzrin, A. M. \& Schmid, A. (2012). Evolution of stabilised creeping landslides. Géotechnique 62, No. 6, 491-501, https://doi.org/ 10.1680/geot.11.P.041.

Puzrin, A. M. \& Sterba, I. (2006). Inverse long-term stability analysis of a constrained landslide. Géotechnique 56, No. 7, 483-489, https://doi.org/10.1680/geot.56.7.483.

Puzrin, A. M., Germanovich, L. N. \& Friedli, B. (2016). Shear band propagation analysis of submarine slope stability. Géotechnique 66, No. 3, 188-201, https://doi.org/10.1680/jgeot. 15.LM.002.

Schlüchter, C. (1988). Instabilities in the area of St. Moritz, Switzerland - geology, chronology, geotechnology. In Proceedings of 5th international symposium on landslides, Lausanne, Switzerland (ed. C. Bonnard), vol. 1, 1375-1380. Rotterdam, the Netherlands: Balkema.

Sterba, I., Lang, H. J. \& Amann, P. (2000). The Brattas landslide in St Moritz. In GeoEng2000: an international conference on geotechnical \& geological engineering, vol. 2, pp. 144-149. Lancaster, PA, USA: Technomic.

Swiss Federal Office of Topography (2019). Federal geoportal. See https://www.geo.admin.ch (accessed 15/07/2020).

Urciuoli, G. \& Picarelli, L. (2008). Interaction between landslides and man-made works. In Landslides and engineered slopes - from the past to the future: proceedings of the 10th international symposium on landslides and engineered slopes (eds Z. Chen, J. M. Zhang, Z. K. Li, F. Q. Wu an and K. Ho), vol. 2, pp. 1301-1307. London, UK: Taylor \& Francis Group.

Viesca, R. C. \& Rice, J. R. (2012). Nucleation of slip-weakening rupture instability in landslides by localised increase of pore pressure. J. Geophys. Res. 117, No. B3, B03104.

Wiberg, N. E., Koponen, M. \& Runesson, K. (1990). Finite element analysis of progressive failure in long slopes. Int. J. Numer. Analyt. Methods Geomech. 14, No. 9, 599-612.

Zhang, W., Wang, D., Randolph, M. F. \& Puzrin, A. M. (2015). Catastrophic failure in planar landslides with a fully softened weak zone. Géotechnique 65, No. 9, 755-769. https://doi.org/ 10.1680/geot.14.P.218. 